\title{
The Southern Star/La Estrella del Sur: zona de contacto bilingüe y traducción en la prensa temprana de Montevideo (1807) ${ }^{1}$
}

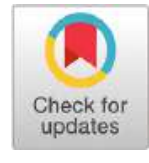

Rosario Lázaro Igoa
rosilazaro@gmail.com Pós-Graduação em Estudos da Tradução, Universidade Federal de Santa

Catarina, Brasil

\section{Resumen}

The Southern Star/La Estrella del Sur, primer periódico uruguayo, fue fundado durante las "Invasiones Inglesas" y duró de mayo a julio de 1807. Tenía formato bilingüe inglés-español y no era dirigido de manera explícita por los invasores. Este trabajo analiza la naturaleza bilingüe del periódico y la relación de las operaciones de traducción, entendida aquí como transediting, con los condicionamientos mediáticos y materiales del órgano de prensa: colaboraciones, formato y características ortotipográficas. Teniendo en cuenta que el periódico no era dirigido necesariamente a un lector que leyera en los dos idiomas, se busca determinar hasta qué punto el inglés y el español funcionan como dos dominios independientes, al tiempo que la dimensión material de la página impresa los aúna. De esta forma, buscamos demostrar que el aparente descuido y la omisión de fragmentos literarios en la traducción del inglés al español responde a una línea editorial consciente de la importancia de la traducción, y que la omisión es consecuencia de una figuración específica del lector en español. Para desarrollar esto, en el artículo primero se discuten los antecedentes críticos sobre el bilingüismo y sobre la traducción en este periódico; luego, se describen las características generales de la relación que establece el bilingüismo, para finalmente analizar las estrategias de traducción en las citas literarias, la red de colaboradores, sobre todo en poesía, y el metadiscurso acerca de la traducción en fragmentos del texto periodístico.

Palabras clave: Edición bilingüe; historia de la prensa; The Southern Star/La Estrella del Sur (Uruguay); traducción de prensa.

\section{The Southern Star/La Estrella del Sur: Bilingual Contact Area and Translation in the Early Press of Montevideo (1807)}

\begin{abstract}
The Southern Star/La Estrella del Sur, Uruguay's first newspaper, was established during the British invasions of Montevideo, spanning its activity from May to July 1807. It was delivered in a bilingual English-Spanish format and was not openly run by the invaders. This work analyzes the bilingual nature of this newspaper and the relationship between translation operations, understood here as "transediting", with the media and material constraints of the publication: collaborations, format and orthotypographic features. Considering that The Southern Star/La Estrella del Sur was not addressed to a reader who could read in both languages, our purpose is to determine to what extent the English and Spanish
\end{abstract}


languages worked as two independent domains, despite being together on the physical dimension of the page. Therefore, we seek to demonstrate that some seemingly negligence and the omission of literary fragments in translated texts into Spanish obey to an editorial line that was aware of the importance of translation, and that omissions are a result of a specific image of the Spanish-speaking reader. With this aim, firstly this article discusses previous critical input about bilingualism and translation in this newspaper; then, it describes the main features of the relationship brought about by bilingualism, and finally it analyzes translation strategies in literary quotations, the network of collaborators - in poetry, especially-, and the metadiscourse about translation in several excerpts of the journalistic text.

Keywords: bilingual edition; history of the press; The Southern Star/La Estrella del Sur (Uruguay); translation in the press.

\section{The Southern Star/ L'étoile du Sud : zone de contact bilingue et traduction dans la première presse de Montevideo (1807)}

\section{Résumé}

The Southern Star/ L'étoile du Sud, le premier journal uruguayen, a été fondé pendant les «Invasions anglaises » et a duré de mai à juillet 1807. Le journal était bilingue anglais-espagnol et n'était pas explicitement dirigée par les envahisseurs. Ce document analyse son caractère bilingue et la relation des opérations de traduction, entendues ici comme transeditting, avec les conditionnements médiatiques et matériels de l'organe de presse : collaborations, format et caractéristiques orthographiques. Les éditions bilingues ont été décrites comme le lieu où s'expriment les différences entre la langue source et la langue cible, parallèlement à l'équivalence supposée entre les deux. Sachant que le journal ne s'adresse pas nécessairement à un lecteur qui lit dans les deux langues, l'objectif est de déterminer dans quelle mesure l'anglais et l'espagnol fonctionnent comme deux domaines indépendants, alors que la dimension matérielle de la page imprimée les réunit. Pour développer cela, l'article aborde d'abord le contexte critique du bilinguisme et de la traduction dans ce journal ; ensuite, il analyse les stratégies de traduction dans les citations littéraires, le réseau de collaborateurs, en particulier dans la poésie, et le métadiscours sur la traduction dans des fragments du texte journalistique. Nous cherchons ainsi à démontrer que l'apparente négligence et omission de fragments littéraires dans la traduction de l'anglais vers l'espagnol répond à une ligne éditoriale consciente de l'importance de la traduction, et que cette omission est la conséquence d'une figuration spécifique du lecteur en espagnol

Mots clés : édition bilingue ; histoire de la presse; The Southern Star (Uruguay) ; traduction de la presse. 
Cuadró la casualidad, o la cola del diablo, que ese año trajeron una imprentita los ingleses, que no se dormían en las pajas, luego que echaron anclas en la plaza a sangre y fuego los de la expedición del caballeresco sir Auchmuty, con cuyo permiso la establecieron el 9 de mayo Isidoro de María (1957, p. 61)

\section{Introducción}

Gracias a la interdisciplinariedad de los estudios de traducción, a la consolidación de nuevos medios de comunicación cuyas condiciones materiales ponen en evidencia lo que influyen en lo que comunican y a la digitalización de vastos corpus de diarios y revistas, los estudios sobre la prensa son un ámbito clave para la disciplina. Valgan tres observaciones acerca de ello: la primera es que esa interdisciplinariedad no es un hecho consumado, sino una condición epistemológica en construcción, como lo demuestra la propia configuración del libro Border Crossings. Translation Studies and Other Disciplines (Gambier y Doorslaer, 2016). Algunos años antes, Doorslaer ya había anotado, en la entrada "Journalism and Translation" del Handbook of Translation Studies, que la interfaz con el periodismo, "el interés por la posición específica de la traducción, como proceso y como producto de la interacción, es relativamente nuevo" (2010, p. 180). ${ }^{2}$ Precisamente, el Grupo de investigación Histoire de la traduction en Amérique Latine, de la Universidad de Montreal (hISTAL, s. f.), sumó desde antes de 2010 la dimensión histórica al periodismo ( $\mathrm{y}$ a la traducción) a las prolíficas investigaciones de ese centro. Otra contribución clave a la confluencia de la traducción y la prensa periódica ha sido el de Patricia Willson (2004a, 2004b, 2011), quien ha investigado el lugar del traductor, la relación entre literatura vernácula y literatura traducida, y el aporte ideológico

2 "[...] the interest for the specific position of translation, both as a process and a product in this interaction, is relatively new". Todas las traducciones de citas con el original como nota de pie de página son nuestras. y estético de la traducción en algunos medios de prensa argentinos. Más recientemente, el número especial de Translation and Interpreting Studies, titulado "Translation and/in Periodical Publications" y organizado por Constanza Guzmán (2019) (quien ya había aportado al tema en Guzmán, 2015, 2017), es una prueba del interés por la confluencia de las mencionadas áreas.

La segunda observación es que el surgimiento de nuevos medios pone de manifiesto la necesidad de analizar la capacidad que tienen esos dispositivos para generar sentido, en lo que Marshall McLuhan (1962) propuso en The Gutenberg Galaxy. The Making of Typographic Man. Esa forma de entender la materialidad de la comunicación y las tecnologías mediáticas, y sus efectos en la traducción, ha sido reivindicada por Karin Littau (2015), al señalar que los aspectos materiales no son solo instrumentos para producir sentido, sino que "establecen el marco dentro del cual algo como el significado se torna posible en último término" (p. 83). ${ }^{3}$

La tercera nota se desprende de la forma en que los medios condicionan las prácticas asociadas a ellos: la progresiva digitalización de corpus de prensa ya ha modificado la manera en que se concibe, realiza y después impacta la investigación. Vale destacar, al respecto, que el presente trabajo parte de varios documentos colecciones de prensa y estudios críticos-que se encuentran en el portal Anáforas, ideado por Lisa Block de Behar. ${ }^{4}$

The Southern Star/La Estrella del Sur (TSS/LES), primer periódico uruguayo, fue fundado durante las "Invasiones Inglesas" en Montevideo, una serie de expediciones militares no exitosas que buscaban anexar el virreinato del Río de

3 "[...] set the framework within which something like meaning becomes possible at all".

$4 \mathrm{El}$ portal Anáforas (s. f.) está ligado al Seminario Fundamentos Lingüísticos de la Comunicación, de la Facultad de Información y Comunicación de la Universidad de la República, Uruguay. 


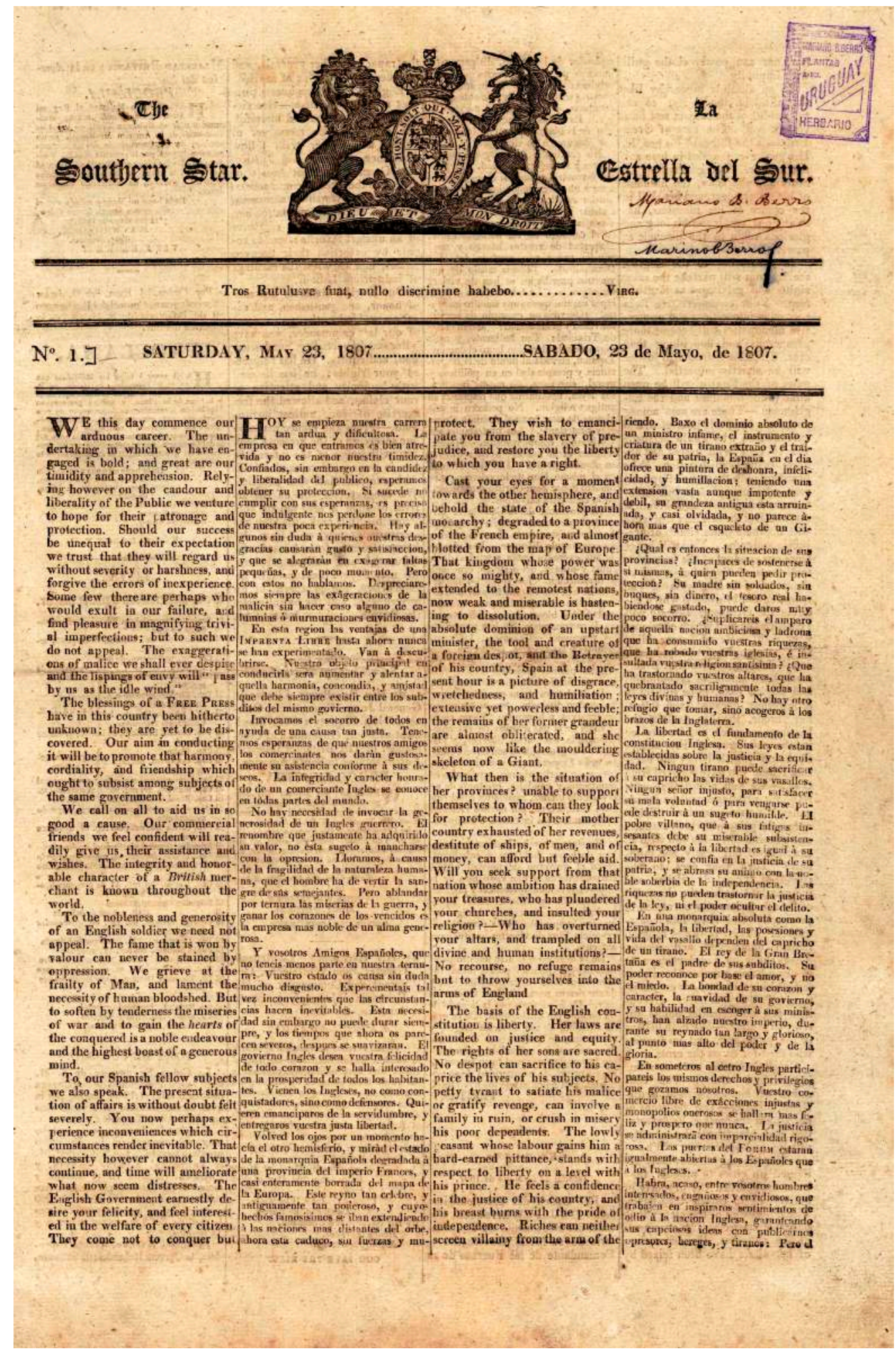

Figura 1. Portada del primer número de The Southern Star/La Estrella del Sur, 23 de mayo de 1807, página 1. Fuente: Anáforas (1807a). 
la Plata al Imperio británico. TSS/LES mantuvo una periodicidad semanal por un tiempo incluso más corto que el de la ocupación de la ciudad: mientras las fuerzas inglesas ocuparon Montevideo del 3 de febrero al 6 de julio de 1807, el periódico fue publicado entre el 23 de mayo y el 4 de julio de aquel mismo año.

La colección consta de siete números, un "Prospectus" anterior (del 9 de mayo de 1807), un "Extraordinary" (del 10 de mayo de 1807) y un "Extra" posterior (del 11 de julio de 1807), cuando los invasores ya habían sido vencidos y debían retirarse de todo el Río de la Plata. Los números habituales y el "Prospectus" tienen cuatro páginas; el "Extraordinary", dos, y el "Extra", una sola hoja impresa de un lado (véase Figura 1).

Desde la declaración de intenciones que es el "Prospectus" del 9 de mayo de 1807, el órgano de prensa indica que publicará noticias de interés general, avisos y extractos de "English and other European papers" / "gazetas inglesas y otras" (p. 3). ${ }^{5}$ Con formato bilingüe inglés-español, no era dirigido oficialmente por los invasores y respondía a la intención de los ingleses de ganarse la simpatía de los montevideanos.

Alicia Torres, al comparar la TSS/LES con la Gazeta de Montevideo, publicación posterior y leal a la colonia, observa:

[...] el hábil discurso de The Southern Star [...] supo divulgar, con eficacia, los valores de la cultura imperial británica, exaltar las bondades de la monarquía constitucional inglesa, defender el principio de libre comercio, celebrar el respeto a los derechos individuales, pregonar la tolerancia religiosa, y, claro, insistir en la decadencia y la injusticia del dominio hispánico y en la incontrovertible ventaja de remover el yugo español (Torres, 2007, p. 34).

5 En todas las citas del periódico se mantienen las marcas ortotipográficas (versalitas, cursivas, mayúsculas etc.) y la grafía originales, incluyendo las faltas de ortografía y la ausencia de la mayoría de los acentos agudos en el español.
Esta habilidad discursiva del "eficacísimo órgano de publicidad de un ejército de ocupación" (González, 2007) fue destacada por los contemporáneos del impreso, como se desprende de los documentos históricos citados asimismo en el prólogo a la edición facsimilar uruguaya de 1942, prologada por Ariosto D. González. Tales documentos confirman el ánimo no belicoso de las páginas de TSS/LES, así como la convivencia del ejército inglés con la población local, durante cinco meses, en 1807.

El contacto lingüístico, que ha quedado plasmado en los ejemplares del periódico, se daba en todos los órdenes de la vida social. "Los extranjeros procuran hacerse entender en español y los montevideanos se esfuerzan por lucir las palabras sueltas de su inglés de diccionario", señalaba el propio González (1942, p. 24). Asimismo, como afirman Bastin e Iturriza (2008) sobre el papel de la traducción en la prensa independentista de Venezuela, en TSS/LES, la traducción en esas páginas también "se convirtió en la negociación de una identidad cultural que daba cuenta de la diferencia cultural, pero también en una herramienta de poder" (p. 83), como demostramos a lo largo de este trabajo.

Como se desprende del epígrafe de Isidoro de María que citamos al comienzo ("Cuadró la casualidad, o la cola del diablo, que ese año trajeron una imprentita los ingleses [...]"), la imprenta vino con las armas. Los invasores, conscientes de la importancia de la esfera mediática para la guerra y la política, llevaron adelante un emprendimiento de prensa escrita: TSS/LES era bilingüe, no oficial de los invasores y con la retórica de la libertad por sobre la obediencia a la metrópolis.

En el prólogo a la edición facsimilar de 2007 de la Biblioteca Nacional Argentina se reafirma su carácter único, en tanto "debe decirse que no roza las formas burdas de este conocido estilo [el netamente propagandístico], sino que se trata de una fina experiencia de publici- 
dad ideológica" (González, 2007, p. 9). Es más, el propio intelectual uruguayo José Enrique Rodó, en un discurso de 1909, ya consideraba que el periodismo en el Uruguay, "meciéndose la cuna de nuestra prensa en las vísperas de la libertad, tuvo por ilustre madrina de óleos a la libre Inglaterra" (1958, p. 4).

En un plano diacrónico, la importancia del órgano de prensa sería tal, que un investigador como William Acree postuló que TSS/LES fue un hito en la forma de hacer política en los inminentes procesos de independencia:

[...] otra batalla, que podemos llamar la batalla retórica, resultó no sólo en la emergencia de lo que sería la cultura impresa en el Río de la Plata, sino también en una transformación en la permanencia de significados y una nueva base de legitimidad para mensajes y acciones políticos (Acree, 2007, p. 13).

El primer periódico de lo que vendría a ser posteriormente Uruguay libró esa "batalla retórica" por medio de algunas innovaciones: el bilingüismo fue una de ellas; la importancia de los avisos comerciales, otra. La recurrencia a la literatura, fenómeno constante en la prensa del siglo XIX, es otra peculiaridad clave de TSS/LES, ya sea en lengua original, como en traducción. Al analizar la presencia de citas literarias clásicas en el periódico, Herrera detecta la promoción del no enfrentamiento: "Los dos acápites ${ }^{6}$ que tuvo la Estrella del Sur sugieren que más que la imagen de conquistadores benévolos, los británicos procuraron imponer la idea de convivencia armónica sin distinción entre invadidos e invasores" (Herrera, 2008, p. 23).

En el presente trabajo, con base en la disposición de los textos en las dos lenguas y en el tratamiento de las citas literarias, analizamos la naturaleza bilingüe de TSS/LES, preguntándonos si esa precisa relación de lenguas en

\footnotetext{
6 "Tros Rutulusve fuat, nullo discrimine babebo" y "Tros Rutulusve mibi millo discrimine agetur". Para una lectura detenida de este aspecto, véase Herrera, 2008 (Nota de la autora).
}

la página impresa es o no "un recordatorio constante de las diferencias entre el idioma de origen y de destino y, paradójicamente, de su supuesta equivalencia uno a uno" (Hewson, 1993, p. 156). ${ }^{7}$ Ya que consideramos que TSS/ LES no era necesariamente dirigido a un público que leyera en las dos lenguas, se busca determinar hasta qué punto el inglés y el español funcionan como dos dominios independientes, al tiempo que la dimensión material de la página impresa los aúna. Como ya mencionamos, nos detendremos en particular en el tratamiento de las citas literarias en TSS/LES, en la red de colaboradores editoriales, básicamente en poesía, y en los pasajes en que es constatable un ejercicio metadiscursivo sobre la traducción.

En primer lugar, presentamos algunas reflexiones de investigaciones anteriores acerca del bilingüismo/traducción en TSS/LES y caracterizamos, con base en investigaciones históricas, la redacción del impreso en el Montevideo de 1807. A continuación, trazamos las características generales de la relación que establece el bilingüismo, para después entrar en asuntos más específicos sobre citas literarias, red de colaboraciones poéticas y metadiscurso sobre la traducción en TSS/LES.

Guía esta investigación la necesidad de "no partir de una visión conciliatoria expurgada de todo conflicto o limitada a los avatares puntuales del cambio de código lingüístico" (Pagni et al., 2011, p. 8), sino de analizar las contradicciones de dos lenguas que conviven en la misma página y los procesos de traducción que ocurren para que así sea. Al articular traducción y condicionamientos mediáticos y comunicativos del órgano de prensa bilingüe, por cierto, se busca tener en cuenta la materialidad en ese proceso, "o sea, las tecnologías, las máquinas y las redes sociales e institucionales

\footnotetext{
7 " $[\ldots]$ a constant reminder of the differences between the source and target languages, and, paradoxically, of their apparent one-to-one equivalence".
} 
que moldean, direccionan y procesan varias formas de expresión e intercambio cultural" (Mitchells, 2010, p. 23). ${ }^{8}$

\section{Aproximaciones al bilingüismo y la traducción en La Estrella del Sur}

Entre los estudios dedicados a TSS/LES, constatamos escasa atención a las especificidades de su naturaleza bilingüe. Lo anterior no es de extrañar, en la medida en que, como releva Roberto Valdeón en "On the use of the term 'translation' in journalism studies", hay un vacío del término "traducción" en las investigaciones que parten del área de periodismo (2018, p. 253). Por cierto, ese vacío se repite en otros abordajes previos del objeto, ya sea tanto desde la historia como desde los estudios culturales. En consecuencia, observamos la desatención hacia las traducciones en la prensa temprana, como apuntan Bastin e Iturriza (2008), planteo que retoma Navarro cuando confirma que "La traducción en la prensa histórica es un objeto de estudio particularmente desatendido" (2011, p. 81). ${ }^{9}$ En el caso específico de TSS/ $L E S$, cuando en las investigaciones aparece una mención al bilingüismo, o a la traducción, como veremos a continuación, es por comentarios generales. Ello se expresa en ocasiones desde la normatividad y no desde el detenimiento en las prácticas específicas, menos atentas a la infidencia, que a la descripción de las operaciones y tensiones entre el inglés y el español en la página impresa.

Ariosto D. González ya señalaba que, en TSS/ LES, "no todos los textos están traducidos" (1942, p. 21), al tiempo que citaba anotaciones de José Toribio Medina en Historia y bibliografia de la prensa en Montevideo 1807-1810, de 1892, sobre traducciones supuestamente "deficientes", porla

8 " $[. .$.$] that is, the technologies, the machines, and$ the social and institutional networks that shape, direct and process various forms of cultural expression and exchange".

9 "La traduction dans la presse historique est un sujet de recherche particulièrement négligé”. forma que adoptaba el español en el que estaban escritas. Analizando solamente el "Prospectus" inicial, González afirmaba que "hay párrafos en los cuales el traductor se extravía sin acertar con la interpretación del original; hay otros mutilados e ininteligibles" (1942, p. 22), dejando en evidencia la normatividad con que se acerca a la traducción en el periódico. Como ejemplo contrario, citaba las cartas que firmó en el periódico Manuel Aniceto Padilla (17801840), periodista peruano de tránsito entre las colonias. ${ }^{10}$ Con el anagrama "Ancelmo Naiteiu", según González, habría firmado textos que serían indicios de "otro molde de expresión; los párrafos breves y claros, si bien no ofrecen una construcción literaria, tienen la animación y el movimiento de las páginas del género" (1942, p. 22). ${ }^{11}$ A partir de estas observaciones iniciales, en definitiva, verificamos una idea de que la traducción, casi siempre anónima, no tendría el nivel de expresión del original inglés y que solamente cuando los textos eran originales en español, es que alcanzarían un modelo deseable de periodismo.

Daniel Álvarez Ferretjans (2008) indica, de manera que discutimos en este trabajo, que TSS/LES contenía "textos idénticos en inglés y español, y con excepción del primero, en columnas alternadas" (p. 38). Por su parte, ya advirtiendo la diferencia entre cada dominio lingüístico, Lisa Block de Behar afirma con más especificidad que este periódico estaría escrito "en inglés y en un mal español" (2015, p. 302), algo que quedará en evidencia a lo largo de este trabajo. Sin embargo, es William Acree quien entra en consideraciones más específicas sobre la relación supuestamente uno a uno del bilingüismo:

10 " $[. .$.$] abogado y periodista vinculado años antes$ al contrabando con Inglaterra en Buenos Aires" (Ares, 2010, p. 96).

11.Será productivo analizar, en una investigación futura, lado a lado las columnas firmadas con este pseudónimo, tomando el español como texto original. 
[...] hay diferencias notables entre las versiones en inglés y castellano, diferencias que tienen que ver con lo que podría ser de interés a los distintos públicos y, más importante, con el deseo de no ofender a los lectores en castellano. Por eso los avisos de remates de telas para los uniformes de los soldados británicos no aparecen traducidos. Había otras noticias específicas, como anuncios en una sola lengua de donaciones a las viudas de soldados ingleses o el nuevo impuesto sobre pulperías, destinado a los lectores montevideanos, que apuntaba a controlar estos espacios de sociabilidad (Acree, 2007, p. 15).

Lo observado por Acree podría explicar la práctica de la omisión como forma de localizar el contenido según el público lector de cada columna de TSS/LES, sobre todo por ser un impreso de los invasores. Sin embargo, es interesante agregar que no solo hay diferencias en los contenidos que se vehiculan, sino también en el modo en que están escritos, en sus rasgos estilísticos, algo que muchas veces se relaciona con los condicionamientos materiales de la página impresa. Como evidenciamos en este texto, la edición bilingüe del periódico se negocia en función de la ocupación inglesa (ausencia de avisos, recomendaciones a lectores criollos o ingleses), pero también de acuerdo con los espacios, las tipografías y la disposición gráfica de TSS/LES, con diferencias significativas en lo que respecta a la introducción de literatura en las páginas en cada lengua. Dentro y entre los dominios del inglés y el español, la traducción adquiere un papel clave, ya sea del inglés al español, o viceversa, o en directa ausencia.

\section{La redacción de La Estrella del Sur: un rompecabezas por resolver}

Las páginas de TSS/LES son espacio de tensión entre lenguas. En cuanto a las prácticas específicas de traducción, observamos las columnas con textos de todo tipo (noticias de guerra, avisos a la población, columnas de opinión) lado a lado, en una supuesta equivalencia, que no demora en revelarse aparente. No hay datos acerca de la identidad de los traductores - más adelante analizamos una excepción-. Allí, en ocasiones, también encontramos inclusión de noticias de otros medios, presumiblemente traducidas, como el "Extract from London Gazette, ${ }^{12}$ March 1, 1807, Capture of Curacoa" (Anáforas, 1807a, p. 3). Hay otras referencias a prensa extranjera, entre las que se destacan los textos contrarios a las campañas de Napoleón Bonaparte, contexto histórico clave de las "Invasiones Inglesas". Por lo tanto, la relación entre el inglés y el español se establece por la versión en dos lenguas de las noticias generales, por la traducción al español de textos ya publicados en otros órganos de lengua inglesa, y por la inclusión de literatura de varias maneras, como analizamos en el apartado 5.1, "Literatura: omitid, que no entienden".

A partir de algunos juicios citados sobre el pasaje entre lenguas, sería posible presumir que el inglés sería el original. Las ediciones bilingües en literatura, como estudia Hewson (1993), en general ofrecen el original a la izquierda y la traducción a la derecha. La versión en español de TSS/LES, en apariencia secundaria (en tiempo y en espacio de la página), es un resultado de la traducción. Sin embargo, en este trabajo preferimos considerar que se presenta la simultaneidad de la práctica bilingüe de edición cuando no hay datos contrarios que indiquen el flujo de una lengua a la otra en todos los casos, así como la coexistencia de varias operaciones textuales, que se podrían denominar transediting (Stetting, 1989, p. 377), o convergencia de traducción y edición en una misma operación. Como revisa y discute Schäffner (2012), esas operaciones (cambios, supresiones, añadiduras, entre otras) forman parte de cualquier proceso traductor y no se circunscriben al ámbito periodístico para el cual el término transediting fue acuñado en su momento, en tanto:

Los cambios a nivel macro y micro forman parte constitutiva de cualquier proceso de

12.En la traducción al español, esa información de la fuente se deja de lado (Nota de la autora). 
traducción, no solamente como resultado de las diferencias entre los sistemas lingüísticos del idioma de origen y del idioma de destino [...] sino, más a menudo, como resultado de las consideraciones del público de destino, la cultura de destino y el propósito que se espera que cumpla el texto de destino en su nuevo contexto (Schäffner, 2012, p. 876). ${ }^{13}$

En la presente investigación se rastrea cómo interactúan noticias en diferentes lenguas sobre la misma página impresa, ${ }^{14}$ incluso en una etapa premoderna en la que los órganos de prensa no se habían transformado en las grandes empresas que un periódico como el argentino La Nación es a fines del siglo XIX (a pesar de que en este caso no fuera dirigido oficialmente por las fuerzas de ocupación) ni tornado tan "global" (como ocurrirá con el cableado transatlántico en la segunda mitad del siglo XIX).

La información acerca de la redacción de TSS/ LES indica que el conocimiento de la prensa no se restringía a los ingleses y que en varios espacios de América existía la conciencia de su utilidad para la lucha política. El escritor e historiador uruguayo Isidoro de María sugirió, desde el mismo siglo, pero con la imprecisión del adjetivo indefinido "tal", que: "Un mister Brandford redactaba la parte en inglés, y unos tales Manuel A. Padilla y Francisco A. Cabello, desempeñaban la parte en castellano" (1957, p. 62). Otros historiadores, consignados en Canter (1948) y González (1942), se dedicaron

13 " $[\ldots]$ shifts at macro- and micro-level are an integral part of any translation process, not only as a result of differences in the linguistic systems of source and target language [...] but more often as a result of considerations of the target audience, the target culture, and the purpose the target text is expected to fulfil in its new context".

14 De todos modos, en este periódico la presencia de noticias extranjeras en original y traducción es menos marcada que lo que Iturriza encuentra en la Gaceta de Caracas (2008, pp. 107-109; 2011, pp. 89-90). al asunto, ${ }^{15}$ por lo que llegada casi la mitad del siglo xx, Ariosto D. González pone en duda varias de las afirmaciones usuales sobre los autores de TSS/LES por medio de acceso a fuentes:

No se conoce, con seguridad absoluta, el nombre del propietario de la imprenta traída por los ingleses en 1807. Se tiene por redactor de LA ESTRELLA DEL SUR sin que se haya publicado documentación fehaciente que lo acredite, a un señor Bradford, que según Medina "no puede ser otro que T. Bradford, el ayudante del Estado Mayor General del Ejército inglés que en ese carácter firmó la orden del día del 4 de Febrero de 1807, después de la toma de Montevideo". El mismo autor, - siempre dentro del terreno movedizo de las conjeturas, - observa que, "en realidad, Bradford sólo fue el redactor de aquel periódico, pero de ninguna manera el industrial dueño de la Imprenta por la que se daba á luz, circunstancia que se habría avenido muy mal con el alto puesto que ocupaba en el ejército". Todo eso descansa en una suposición (González, 1942, p. 18).

Según González, en aquella redacción sí habría estado Bradford, con auxilio de algún otro conocedor del inglés cuando debía embarcarse en campañas militares. No sería viable pensar que Francisco Antonio Evaristo Cabello y Mesa ${ }^{16}$ hubiera participado, pero sí Manuel

15 Véanse estos estudios para un panorama de fuentes, estudios históricos y discusiones hasta mitad del siglo xx.

16 La participación de Cabello y Mesa hubiera sido una nota más a la excepcionalidad del impreso. Francisco Antonio Evaristo Cabello y Mesa (1764-1830) era un español prisionero al momento de la segunda invasión, que también escribía con el seudónimo de "Jaime Bausate y Mesa". Según investiga Martini (1998), fue el editor del primer diario hispanoamericano en 1790 , el Diario de Lima, y del inaugural Telégrafo Mercantil, rural, político-económico e bistoriógrafo del Río de la Plata de Buenos Aires, en 1801. "Periodista, dramaturgo, gramático, traductor, superintendente de las minas de Almadén, caballero de la Orden Real de España, catedrático de cultura española en el co- 
Aniceto Padilla. Juan Canter, en la "Introducción" a la Biblioteca de impresos raros americanos también refuta la idea, difundida, de que Cabello y Mesa fuera parte de la redacción (1948). Por otro lado, Castellanos ya había investigado la identidad del seudónimo "Veritas", que atribuyó a William Scollay, estadounidense egresado de la Universidad de Harvard, dato que se apoya, además, en las numerosas citas literarias y referencias históricas en las páginas del periódico (Castellanos, 1943). Lo que Canter sí reafirma, con base en estudios anteriores, es la participación de Manuel Aniceto Padilla en aquel grupo de personas encargadas de publicar TSS/LES.

A pesar de estas aclaraciones, se sigue sugiriendo, matizada, la presencia de Cabello y Mesa en libros recientes, como Expósitos, la tipografia en Buenos Aires: "Bradford contó con la colaboración del criollo Manuel Aniceto Padilla, [...] y se afirma que también con la colaboración del escritor español Cabello y Mesa" (Ares, 2010, p. 96). ${ }^{17}$ Esa información coincide con lo que ya había indicado el Índice cronológico de la prensa periódica del Uruguay 1807-1852 (Praderio, 1962), sin cita de fuentes.

En la Historia de la prensa en el Uruguay, Álvarez Ferretjans observa asimismo la participación

legio Louis le Grand de París", como se indica en la entrada correspondiente de la Real Academia de la Historia (2018). Autor de una obra tardía que condensa su tránsito entre imperios: Mosaico gramatical en coloquios didascálicos para servir de suplemento a la gramática sinóptica francesa castellana (Madrid, 1824). Se habría exiliado en Francia, donde se desempeñó como traductor (Marco, 2006, p. 30).

17 Ares también comenta que, terminada la invasión inglesa, la imprenta fue vendida a Buenos Aires, con lo que "La Imprenta de Expósitos duplicó su capacidad de trabajo gracias a las Invasiones. Su fondo se incrementó con una prensa superior a la que había tenido por casi treinta años, y con tipos 'modernos' dotados de sus respectivas cajas y chibaletes, y 100 resmas de papel, 48 resmas de ordinario, marca regular, y 52 de marca mayor" (Ares, 2010, p. 101). de una poetisa, "María Theresa, la que de haber existido, hubo de ser, sin lugar a dudas, la primera mujer que escribió en una publicación periodística en el Río de la Plata" (2008, p. 34), y da por terminado el asunto que nos interesa, al señalar: "no se ha logrado identificar con certeza el nombre de los redactores o periodistas" $(2008$, p. 34$) .{ }^{18}$

La pregunta de quiénes fueron los redactores, si bien sigue en cierta forma abierta, no deja de sugerir la presencia de ingleses y criollos en la redacción, así como la existencia de colaboradores de diversos orígenes para que el periódico cumpliera con la periodicidad semanal. Este dato sobre la red de colaboradores, que luego veremos se extiende entre los lectores, es fundamental para entender la manera en que se puede realizar un periódico semanal en Montevideo en 1807. Al mismo tiempo, la publicación de TSS/LES ocurre en un contexto en el que los criollos fueron receptivos de esta nueva forma de comunicación masiva.

Como observa Pierrotti, hacia principios del siglo XIX, el comercio de libros estaba en manos de particulares y había algunas copiosas bibliotecas, aunque la Biblioteca Pública de Montevideo se fundó en 1816 :

Todo el conjunto de datos sobre las bibliotecas coloniales $[. .$.$] marcan claramente un cam-$ bio desde la primera mitad del siglo xVIII mucho más "devota" hacia una cultura ilustrada más vasta y diversificada en cuanto a temas y en cuanto a tamaño (Pierrotti, 2008, p. 144).

No obstante, Pierrotti, en otro artículo académico, destaca la observación de José Joaquín de Viana, quien en 1755 afirmaba: "No pocos

\footnotetext{
18 Álvarez Ferretjans anota que: "No se limitó la imprenta inglesa a la propaganda en la Banda Oriental. La Estrella del Sur se expandió más allá de los muros coloniales montevideanos, hasta llegar incluso a manos de Francisco de Miranda (Caracas, 1750-1816), el precursor de la emancipación política de la América española, en cuyo archivo se conserva un ejemplar" (2008, p. 35).
} 
de los que componían el Cabildo no sabían leer, ni escribir" (apud Pierrotti, 2007, p. 38). Sin embargo, la convivencia forzada por la invasión inglesa debe haber derivado en un interés de ambas partes, aunque fuera netamente utilitario, por la política, la cultura y la lengua del otro, como ejemplifica un elocuente aviso solo para la columna en español de TSS/LES:

\section{DON DAVID CREIGHTON,}

Avisa a las Señoras y Señores de Monte-Video.

Que piensa dedicarse algunas horas del dia a la instruccion de un numero selecto de discipulos en la lengua Inglesa. Aquellas personas que quieran aprenderla podran recebir mayor informacion en la Calle de San Diego, No. 54 ([Aviso]. Anáforas, 1807e, p. 4).

Este aviso demuestra que la convivencia entre lenguas no se daba solamente en las páginas de TSS/LES, sino que abarcaba numerosos ámbitos de la vida montevideana en aquellos cinco meses de 1807. La precisa disposición bilingüe a dos columnas del impreso, sus características ortotipográficas y la introducción de literatura reafirman la unicidad del emprendimiento y su manifestación en el plano mediático, como veremos a continuación.

\section{Edición bilingüe: consideraciones teóricas y materialidad en la página}

Las ediciones bilingües son entendidas como aquellas en las que todas las palabras, o los textos, se presentan en una lengua y son traducidos a una segunda lengua. Para su estudio se analiza la forma en que el texto primario y la traducción están dispuestos sobre la página, y en qué tipo de fuentes, de manera que se trata de un objeto de estudio que superpone diseño gráfico con aspectos lingüísticos y literarios (Sarkonak y Hodgson, 1993, p. 20). De este modo, para el caso concreto de TSS/LES, las interrogantes que trabajamos fueron: ¿cuál es el vínculo entre los diferentes textos, la presentación gráfica y las estrategias de traducción?
¿Se identifican los autores y las fuentes de las traducciones? ¿Y las fuentes? ¿Hay estrategias coincidentes entre texto fuente y texto de llegada según la supuesta lengua original del texto, asumiendo que no siempre debe ser aquella de la columna de la izquierda?

Otro de los elementos constitutivos de una edición bilingüe es la visibilidad que la coexistencia de lenguas adquiere en el texto (Sarkonak y Hodgson, 1993, p. 22). Al respecto, Hewson crea un estatuto especial para la traducción que ocurre en la edición bilingüe (p. 140). Esa traducción expuesta, explícita, a la que hace referencia al estudiar las ediciones bilingües de textos literarios, en las que los lectores pueden ir y venir entre las dos áreas de la página, es distinta a la que nos ocupa en este trabajo: en TSS/ $L E S$, se prefiguran lectores en las dos lenguas, aunque no necesariamente todos esos lectores leyeran inglés y español con competencia. Sin embargo, más allá de la duda acerca de cuán conscientes de la relación entre las dos lenguas eran los lectores montevideanos e invasores, a los ojos de la investigación actual, el texto original sí es visto "a la luz de la traducción que ha experimentado" (Hewson, 1993, p. 155) ${ }^{19} \mathrm{y}$ es desde ese lugar que lo sometemos al análisis.

Toda la construcción bilingüe de TSS/LES se apoya en la disposición sobre la página impresa. Las investigaciones pioneras ya observaban las innovaciones gráficas que introducía. Canter incluso apuntó que "la impresión inglesa es muy superior a cualquiera de los Expósitos bonaerenses. La marca europea queda patentizada en un estilo que no era el rioplatense" (1942, p. lii). González hizo observaciones similares sobre el periódico, del cual resaltaba:

La calidad del papel utilizado, el buen estado $\mathrm{y}$ variedad de los tipos y medidas, el formato de las páginas mucho mayor que el de las publicaciones periodísticas bonaerenses, la composición adecuada y llamativa de los anuncios, el ajuste y claridad de las impresiones,

19 "[...] seen in the light of the translation that it has undergone". 
evidencian que los medios y el instrumental de ese taller son bastante eficientes y completos. Como singularidades, cabe destacar la existencia de la letra $\tilde{n}$, ajena al alfabeto inglés, y la escasez de vocales acentuadas, que sólo se usan aisladamente y casi nunca cuando integran palabras $(1942$, p. 18$)$.

Así, TSS/LES presenta cuatro columnas por página, siendo la primera y la tercera columna (impares) en inglés, y la segunda y la cuarta (pares) en español. Como veremos a continuación, eso ocurre en la primera y la segunda página, en un equilibrio correlativo que se va alterando (el texto en español ocupa más espacio, en general, a pesar de que sea presentado con una fuente menor y menos adornos gráficos), hasta que, en la página 4 , las columnas incluyen texto en inglés, seguido del texto en español, en la misma columna. En esta última página están también los avisos, que no siempre se traducen, según a quien estén dirigidos, lo que altera aún más la supuesta equivalencia uno a uno del formato bilingüe.

El primer número del periódico ejemplifica lo que fue señalado: el formato inicial es en cuatro columnas, con una fuente levemente más pequeña en el texto español (véase Figura 2).

W $\mathrm{E}$ this day commence our $/ \mathrm{H}^{\mathrm{OY}}$ se empieza nucstra carrerp/protect. They wish to emanci- riendo. Baxo cl dominio absoluto de

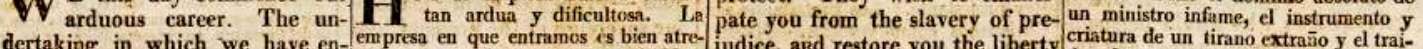
gaged is bold; and great are our vida $y$ no es menor nuestru timidez. timidity and apprebension. Rely- Confiados, sin embargo en la candidtz to which you have a right. ofrece una pintura de deshonra, infelitimidity and appreheision. Rely- y liberalidad del publico, esperamos Cast your eyes for a moment cidad, $y$ humillacion; teniendo una ing however on the candour and obtener su proteccion. Si sucede no towards the other hemisphere, and extension vasta aunque impotente $y$ liberality of the Publie we venture cumplir con sus esperanzas, is preciso tow the state of the Spanish debil, su grandeza antigua esta arruinto hope for their fatronage and que indulgente nos perione los errorrs vehold the state of the Spanish ada, $y$ casi olvidada, $y$ no parece àprotection. Should our success de nuestra poca experi-ncia. Hay al- movarchy; degraded to a province hora mas que el csqueleto de un Gibe unequal to their expectation gunos sin duda ì quims aucstras des- of the French empire, and almost gante.

we trust that they will regard us gracias causaràn gusto y satisfaccion, blotted from the map of Europe. iQual cs entonces In siteacion de stis we trust that they will regard us y que se alegraràu en exagrar faltas That kingdom whose power was provineias? ¿Incrpaces de sostenerse d without severity or harshness, and pequeñas, y de poco momuto. Pero once so mighty, and whose fame si nismas, d̀ quirn pucden pedir proforgive the errors of inexperience. con estos no hablamos. Dispreciare- once so mighty, and whose fame teccion? Su madre sin soluados, sin Some few there are perhaps who mos siempre las exígeracioncs de la extended to the remotest nations, buques, sin dinero, cl tesoro real ha.

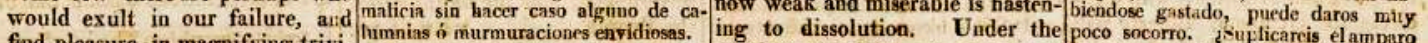
find pleasure in magnifying trivi- himnias $\dot{\theta}$ murmuraciones envidiosas. ing to dissolution. Under the poco socorro. ¿supticarcis el amparo al imperfections; but to such we En esta region hs ventajas de una absolute dominion of an upstart de aquella nacion anbicinsa y ladrona do not appeal. The exaggerati- se han experimentado. Van à descu- a foreign des, ot, and the Betrayer que ha rabalo vuestras iglesias, é inons of malice we shall ever despise brirse. Nustro objto pritacipłt en of his country, Spain at the pre- sultada vuestrartigion santisima? ¿Que and the lispings of etivy will " $[$ ass conducirla scra aumentar $y$ alentar a- of his country, Spain at the pre- ha trastornado vuestros altares, que ha by us as the idle wind." quella harmonia, concondia, $y$ amjstad sent hour is a picture of disgrace, quebrantado sacriligarnente todas las The blessings of a Free Press que debe siempre existir entre los sub- wretchedness, and humiliation; leyes divinas y humanas? No hay ntro have in this country been hitherto ditos del mismo govierno. $\quad$ exteusive yet powerless and feeble; refugio que tomar, sino acogeros à los have in this country been hitherto. Invocamos el socorro de todos en the remains of her former grandeur brazos de la Inglaterra. unknown; they are yet to be dis- ayuda de una cuusa tan justa. Tene- are almost obliterated, and she La libertad es ef fundamento de la covered. Our aim in conducting mos esperanzas de que nuestros amigos are almost obliterated, and she constitucion Inglesa. Sus leyes estan it will be topromote that harmony, los comerciantes nos daràn gustos-i- seerns now a Geleton of a Giant. cordiality, and friendship which mente su asistencia conforme à sus de- skeleton of a Giant. What then is the situation of isu capricho las vidas de sus sasificir ought to subsist among subjects of
do de un comerciante Ingles se eonoce her provinces? unable to suppori Ningun seiior injusto, para satisfacer the same government. en todas partes del mundo. We call on all to aid us in so No hay ncoesidad de invocar la ge- themselves to whom can they look ede destruir à un sugeto humilde. LI good a cause. Our commercial ncrosidad de un lngles gucrero. El for protection? Their mother pobre villano, que ḋ sus fitigns infriends we feel confident will rea- renombre que justamente ha adquirilo country exhausted of her revenues, sesantes debe su miserable subsistendily give us, their assistance and sn valor, no esta sugeto ì manchars destitute of ships, of men, and of cia, respecto à la libertad es igusid it su wishes. The integrity and honor- con la opresion. Lloramos, à cansa money, can afford but feeble aid. soberano; se confia cn la jnsticia de su wishes. The integrity and houor- de la fragilidad de la naturnleza huma- Will you seek support from that patria, y se abrasa su animo con la su-
able character of a British mer- na, que el hombre ha de vertir la san-

Figura 2. Formato de cuatro columnas de la página 1 del número 1 de The Southern Star/ La Estrella del Sur (recorte). Fuente: Anáforas (1807a).

Si bien la edición comienza a cuatro columnas alternadas, ya en la página 4 del mismo número las noticias van una a continuación de la otra en la misma columna (véase Figura 3).

El diseño, que comienza siendo coincidente, pero que evoluciona a un criterio diferente en la organización de las noticias, genera una cierta perplejidad al momento del análisis, inclusive el que no es comparado. Podemos aventurar que, para un público montevideano no habituado a la lectura de prensa, esa perplejidad debe de haber sido más acentuada.

Prueba de la selectividad de los textos presentados en cada lengua, en la misma página 4, más 


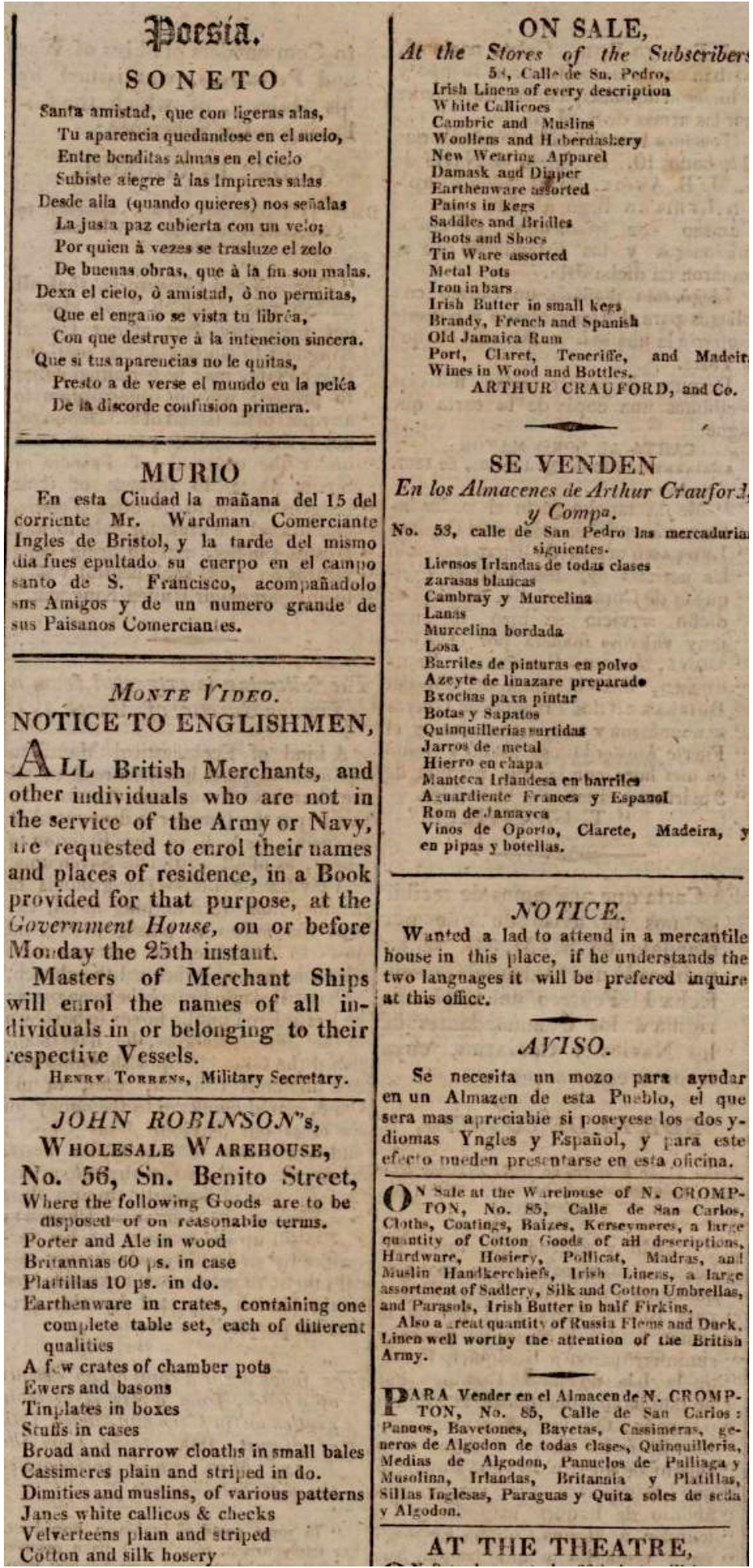

Figura 3. Formato de noticias seguidas, en la página 4 del número 1 de The Southern Star/ La Estrella del Sur (recorte). Fuente: Anáforas (1807a). 


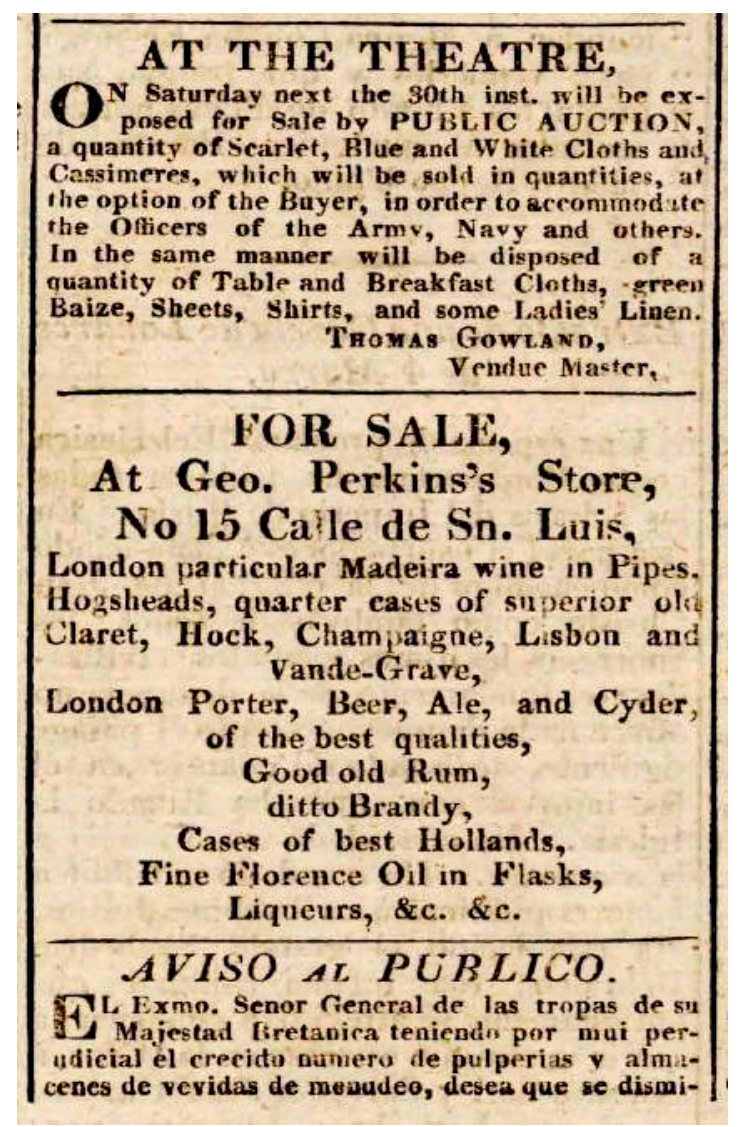

Figura 4. Avisos no traducidos al español, en la página 4 del número 1 de The Southern Star/La Estrella del Sur. Fuente: Anáforas (1807a). abajo, hay dos avisos que no son traducidos al español, por lo que se infiere que los montevideanos no eran destinatarios de la venta de estas mercancías (véase Figura 4).

Observamos que las omisiones de numerosos avisos comerciales (en inglés) en la versión en español se repiten a lo largo de los siete números. En el número 4, en la página 4, como ya señalaba Acree (2007, p. 15), hay una columna entera en inglés que no se traduce al español, con noticias, entre otras, de una colecta a nombre de las familias de los soldados ingleses caídos en el sitio. Ello lleva a pensar en la figuración precisa del público al que se dirigían los contenidos periodísticos en cada lengua.

Como ya se mencionó, hay igualmente diferencias en los párrafos (sangrías no coincidentes, eliminación de párrafos) para adaptar los tamaños del texto en cada lengua al espacio disponible. Las estrategias no siempre se mantienen en el inglés y en el español, aunque sí identificamos ocasiones en que el español se adapta al inglés: a medida que el texto avanza, la columna pierde espacio y se anulan los párrafos en español, como en el Ejemplo 1 que transcribimos (noticia naval) y que a continuación mostramos en la Figura 5.

\begin{tabular}{|c|c|}
\hline $\begin{array}{l}\text { N. B. The Duguay Trouin and Scipion } \\
\text { totally dismasted; the Formidable and } \\
\text { Mont Blanc have their foremasts standing. } \\
\text { Our Frigates-Santa Margarita, Elolus, } \\
\text { Phonix, and Revolutionaire. } \\
\text { The Revolntionaire joined at the time } \\
\text { the Namur did, but, with the rest of our } \\
\text { frigates, in consequence of the French } \\
\text { tacking, were to leeward of the enemy. } \\
\text { I do not know what is become of the } \\
\text { Bellona, or the other two sail we saw on } \\
\text { the night of the } 2 \text { d instant. } \\
\text { The reports of damage, killed, and } \\
\text { wounded, have notbeen all receired. The } \\
\text { enemy hare suffered much. }\end{array}$ & $\begin{array}{l}\text { Scipion } \\
\text { P. D. El Duguay Trouin y Scipion que- } \\
\text { daron con sus mastiles enteramente peridos, } \\
\text { y el Formidable, y el Mont Blanc, tienea } \\
\text { sus trinquetes todaria. Nuestras fragats- } \\
\text { Sta. Maria, Lolug, Phenix, y Revolutis } \\
\text { onare. La Retolutionare se unió al mis- } \\
\text { mo tiempo que Namur, y el resto de nues- } \\
\text { tras fragatas á causa de haber dado otro } \\
\text { bordo los Frarceses, estaban ál sotavento. } \\
\text { No se donde está la Belona y otras dos } \\
\text { relas que vimos la noche del } 2 \text { del cor- } \\
\text { riénte. No he recivido aun las razoues de } \\
\text { los deterioros, muertos y heridos. El } \\
\text { enemigo padeció mucho. }\end{array}$ \\
\hline
\end{tabular}

Figura 5. Ejemplo de adaptación del español al inglés en The Southern Star/La Estrella del Sur, número 6, 27 de junio de 1807, página 1 (recorte). Fuente: Anáforas (1807e). 


\section{Ejemplo 1}

N. B. The Duguay Trouin and Scipion totally dismasted the Formidable and Mont Blanc have their foremasts standing.

Our Frigates-Santa Margarita, AEolus, Phœenix, and Revolutionaire.

The Revolutionaire joined at the time the Namur did, but, with the rest of our frigates, in consequence of the French tacking, were to leeward of the enemy. I do not know what is become of the Bellona, or the other two sail we saw on the night of the $2 d$ instant. The reports of damage, killed, and wounded, have notbeen all received. The enemy have suffered much.

Fuente: Anáforas (1807e, p. 1).

Por otra parte, a rasgos generales se nota menos cuidado en los aspectos gráficos de la versión en español del texto. Véase, en la Figura 6, la ornamentación del texto en inglés gracias a la oscilación de mayúsculas y minúsculas, recurso del que carece la columna en español por cuestiones de espacio. En dicha figura, lo que vendría a ser título en inglés ("COMPLETE VICTORY") que-
P. D. El Duguay Trouin y Scipion quedaron con sus mastiles enteramente peridos, y el Formidable, y el Mont Blanc, tienen sus trinquetes todavía. Nuestras fragata-Santa Maria, Eolus, Phenix, y Revolutisonare. La Revolutionare se unió al mismo tiempo que Namur, y el resto de nuestras fragatas á causa de haber dado otro bordo los Franceses, estaban ál sotavento. No se donde está Belona y otras dos velas que vimos la noche del 2 del corriente. No he recivido aun las razones de los deterioros, muertos y heridos. El enemigo padeció mucho.

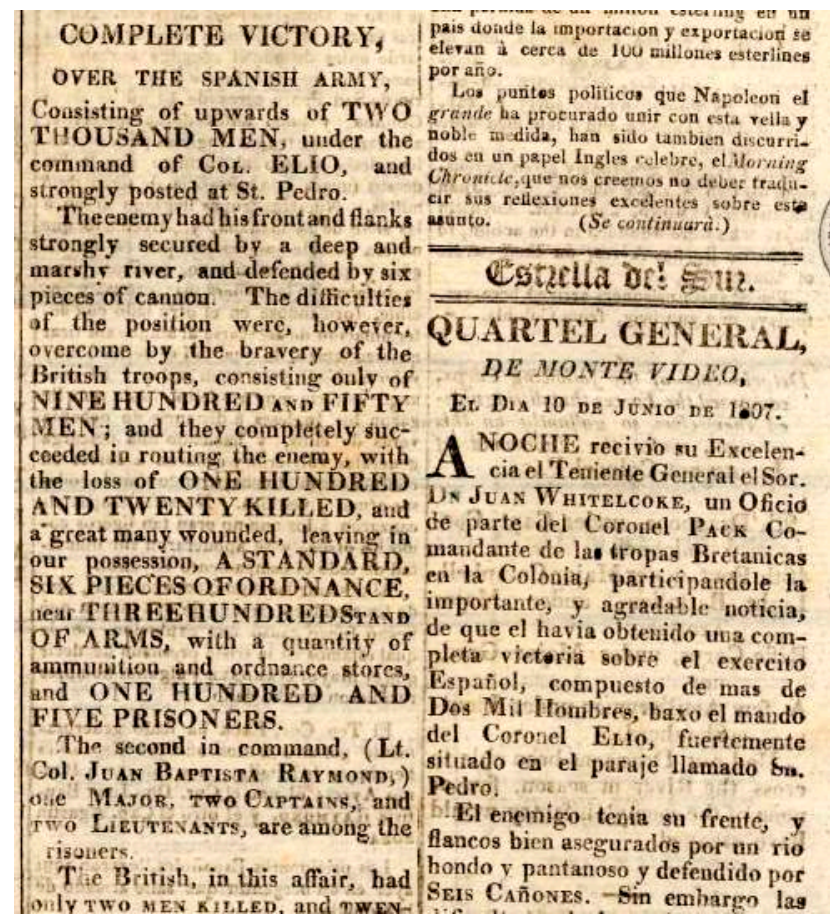

Figura 6. Cuidado de aspectos gráficos según el idioma en The Southern Star/La Estrella del Sur, número 4, 13 de junio de 1807, página 3 (recorte). Fuente: Anáforas (1807c). 
Ese descuido por los aspectos gráficos del texto en español se repite en la reproducción de una noticia del periódico $L^{\prime} A m b i g u$ de Jean-Gabriel Peltier, contrario al ejercicio político de Napoleón Bonaparte. Frente al bloqueo de Inglaterra por parte de Napoleón, la noticia afirma que los franceses no serían capaces de tomar las mismas determinaciones si fuera el caso.

En el número 4 de TSS/LES, del 13 de junio de 1807, en la página 3 (la reproducción de la noticia sigue en el número 5 del 20 de junio de 1807) (véase Figura 7), se nota un criterio aleatorio en el uso de las cursivas en tanto recurso irónico: no todos los términos en francés, de los que casi se burla el texto al colocarlos en lengua extranjera, son reproducidos y marcados en cursivas como en inglés.

Por ejemplo, en esta noticia del 13 de junio de 1807, se elimina el adjetivo "pot-valour" (versión arcaica de "pot-valiant", alusivo al sujeto envalentonado por tomar alcohol), que queda cambiado por "repuesto de votellas"; los miembros del comité de la revista Almanach des Gourmands, que por ser un medio de prensa igual iría en cursivas, se transforman en español simplemente en "golosos"; se mantiene la referencia al postre "blanc manger" en cursivas y la histórica tabaquería francesa À la Civette se mantiene de la misma manera, pero en cursivas, "Civette".

En función de lo expuesto, consideramos que hay consciencia del uso del recurso visual que las cursivas representan (lengua extranjera; uso, aunque equivocado, para determinados elementos del discurso; y, simplemente, forma de destaque). Como prueba, es que en español aparece, erróneamente, en el topónimo "Thuilleries" y en la traducción, ahora sí, de la expresión "qui l'ame tant" por "amante que tanto la $a m a$ ", en la que se traslada el uso de las cursivas por alusión al francés desde el texto en inglés, al uso como manera de destaque en el texto en español, con efectos diferentes. Así, podemos pensar en que el uso, en apariencia aleatorio, corresponde a ciertas coordenadas culturales e ideológicas, y en ocasiones al desconocimiento o la falta de criterio editorial. same manner every day in the week. It the British government were susceptible of suffering itself to be agitated by heroical fits of rage, like these hostilities in wine, and this kind of pot-valour, there would not be found at Paris, nor eren on th continent, a cup of tea, to assuage tik pains of a cholic, or a pound of nutmeg or pepper, for the committee of the $A l$ manach de Gourmands; nor wherewith ec give confits to the little dynasty-or, to burn sugar in the dressing-room of $\mathbf{J}$ oseph. ine-or, to make a blanc manger for Cainbaceres-or, a glass of lemonade for the poets of the National Institute-or, a rol of tobacco, to supply the magazine of the Cipette, and the guasds of the Thuilleries -or, a camel's hair shawl, for Mademoicelle Georges, who would not eren be able to offer a cup of cofiee to fier illustrions lover qui l'aime tant. On the other trand

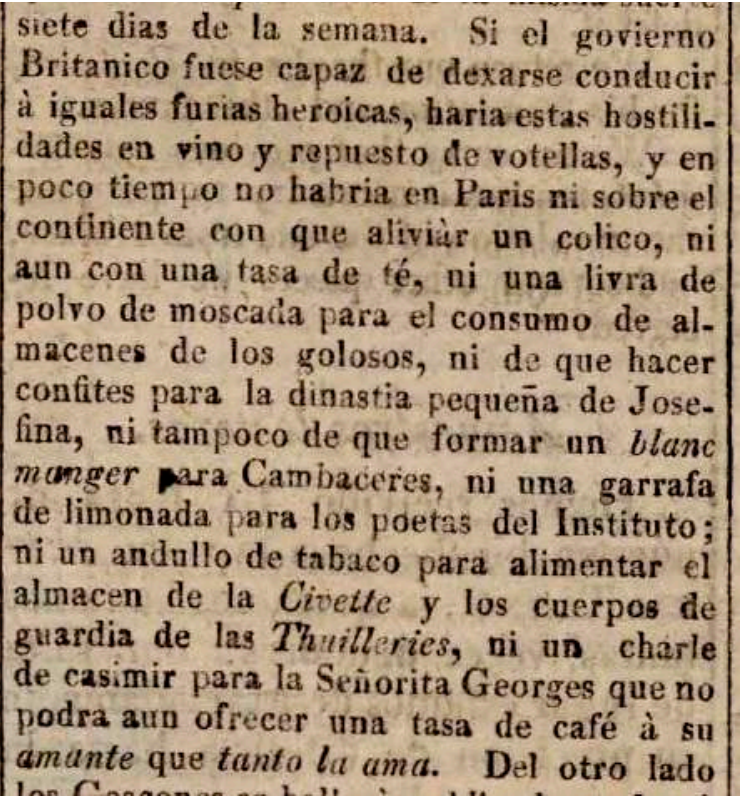


Otra evidencia del descuido con relación a las convenciones ortotipográficas en el texto en español la representa la forma en que se realizan las citas directas en un mismo texto de opinión firmado por Peltier y titulado "The Catechism of Bonaparte" y "El Catezismo de Bonaparte" (1807, p. 2) (véase Figura 8). Mientras las palabras de Jesús, "Go and instruct the nations" se reproducen también entre comillas en español ("Andad y enseñad á las naciones"), en la siguiente columna, cuando existe una referencia a los deberes de los súbditos con relación a Napoleón, mientras en inglés hay una reproducción del texto, en español se suprimen las comillas, como si el contenido de cada cuestión fuera escrito por el propio Peltier. Esta operación deja en evidencia una figuración del lector en español menos ilustrada que su contraparte en inglés.

which if we are authorised to distrust, we are not authorised to accuse.

There is bowever one article which strikes and even shocks us, it is that of the duties of subjectstowards the princes who govern them; their duties toward the new emperor. This is the subject an entire cliapter, Lesson First, on the fourth commandment. It contains five questions, every one of which is worthy attention.

Question first. "What are the duties of christians, with regard to princes wio govern thein; and espocially what are the duties we owe to Napoleon I. our empetor?"

Answer. "W We owe, especially to Napoleon I. our Einperor, Hove, respect, otedience, fidelity, military service, tribute ordained for the preservation of the cmpire and of his throne \&c. \&t. \&c.

If it please the compiler, we owe none of these duties to Napolcon $I$.

We do not owe him love, he has done nothing to make himself beloved: he has done every thing to render him. self hated: by his dark and ferocions
En función de estas observaciones sobre el equilibrio variable de columnas, la estructura no coincidente de los párrafos, la diferencia en el cuidado ortotipográfico entre el inglés y el español y la no traducción de avisos, podemos señalar que las diferencias entre los dominios del inglés y del español en TSS/LES tienen que ver con las estrategias de transediting, llevadas a cabo en torno a lo que los editores suponían que le interesaba a cada público.

Pensamos, por otra parte, que entran en juego aquí cuestiones de extensión del texto traducido al español, visiblemente más largo, y un descuido en los elementos gráficos del texto, posiblemente por falta de profesionalismo, algo que en las redacciones rioplatenses recién ocurrirá a fines del siglo XIX (Henríquez Ureña, 1980, p. 207). Cabe tomar en cuenta aquí también la subestimación, desde un prejuicio perador. Esta es la materia de ún capitulo entero. Leccion primera sobre el quarlo mandamiento. Contiene cinco qüestiones, todas ellas merecen atencion.

Qüestion primera. ¿ Quales son los deberes de lós Ghristianos respecto ù los principes que los goviernan, $y$ quales son en particular nuestros deberes hàcia Napolicon $I_{0}$. nuestro Emperador?

riespuesta. Debemos en particular ¿ Napoleon 10. nuestro Einperador el àmor el respeto lá obediencia, la fidelidad, el servicio militar, los tributos ordenados para la conservaciou del imperio $y$ de su trono \&c. \&c.

Que no disguste al redactor, no se debe nada de esto à Napoleon lo.

No se le debe el amor: no ha hecho nada para ser amado: lo que ha hecho es para ser aborrecido por su humor sombriò y f srox, $y$ por la violenciá de su caracter, molesta a todos los que le rodean : por su furia de conquistas molesta à toda la Luropa.

No se le debe el respeto à él que nada ha respetado, ni aun al trono pontificio que se jactaba haber aniquilado: ni la

Figura 8. El uso de las citas directas en The Southern Star/La Estrella del Sur, número 6, 27 de junio de 1807, página 2 (recorte). Fuente: Anáforas (1807e). 
Ejemplo 2

To our Spanish fellow subjects we also speak. The present situation of affairs is without doubt felt severely.
Y vosotros Amigos Españoles, que no teneis menos parte en nuestra ternura: Vuestro estado os causa sin duda mucho disgusto

Fuente: Anáforas (1807a).

más o menos sutil, del lector del texto en español desde una redacción llevada a cabo por los invasores. Como veremos a continuación, estas características se suman a otras, como la retórica del texto y la sofisticación o no en el plano de la intertextualidad literaria, que apoyan esa interdependencia entre la orientación política de TSS/LES, su realidad mediática y la tensión entre los dos dominios lingüísticos.

\section{Rasgos de la relación entre las columnas}

Antes de pasar al análisis de la traducción de las citas y los textos literarios, es útil hacer un sumario de ciertos rasgos de la relación entre los textos en inglés y español de TSS/LES. En el primer número, del 23 de mayo de 1807, en el que bosqueja la línea editorial, hay diferencias notables en la sintaxis, que no siempre están alentadas por los usos en cada lengua. El inglés aparece en un uso más complejo, mientras que el español hace operaciones que no siempre se pueden explicar como errores de traducción, sino ejemplos de transediting. Observamos añadiduras y cambios que localizan al texto en español, como en el Ejemplo 2, tomado del número 1, del 23 de mayo de 1807, página 1.

Lo anterior es una reafirmación, en el texto en español, de la voluntad de los invasores por mejorar las condiciones de vida de los montevideanos, lo que se lograría, en español, por medio de la apelación a la sensibilidad (la "ternura", que está ausente en el texto en inglés).

En línea con esta estrategia, en la misma página vemos un cambio en el tono del discurso: "generous mind" se torna "alma generosa" en español. El Gobierno inglés estaría "earnestly" ("honestamente") interesado en mejorar las condiciones de los ocupados, que en la columna en español se transforma en "de todo corazón".

Otro ejemplo, del mismo número, pero de la página 2 , en lo que viene a ser la larga columna firmada por "Veritas", muestra que "affection" ("afección" o "cariño") se transforma en un sentimiento decididamente más candoroso, es decir, en "amor" (véase Ejemplo 3).

Este último fragmento ejemplifica, además, un rasgo que se repite a lo largo de los siete números de TSS/LES: la profusión de faltas de ortografía ("gefe", ausencia de determinados acentos) y problemas de gramática en español (la inversión y adición "soberano gefe presente"). Las numerosas citas que presentamos, en las que se mantiene la ortografía original, reafirman la observación del "mal español" de Block. Asimismo, se detecta, en otro plano que tiene que ver con la apropiación de algunos elementos de la cultura extranjera, la traducción de los nombres propios del inglés al español, como ya anticipa la página 2 del número 1 , del

\section{Ejemplo 3}

From the choice made by our sovereign of the present Chief, you will judge of the interest he has in your welfare, and of his wishes to conciliate your affection

De la elección que hizo nuestro soberano del gefe presente podeis juzgar del interes que tiene en vuestra felicidad, y de sus deseos para adquirir vuestro amor.

Fuente: Anáforas (1807a). 


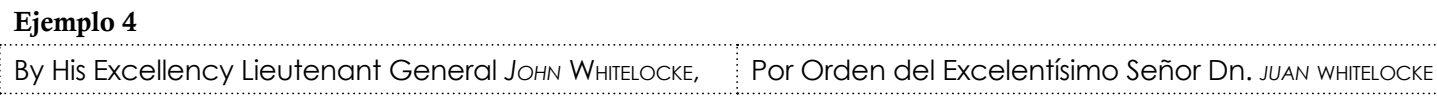

Fuente: Anáforas (1807a).

23 de mayo de 1807 , en que se traduce "John" por "Juan" (véase Ejemplo 4).

En la misma página, que detalla una lista de la oficialidad inglesa en Montevideo, leemos la traducción de "Charles Maxwell" por "Carlos Maxwell", de "Wm. Lumley" por "Guillermo Lumley" y de "Henry Torrens" por "Henrique Torrens", además de la falta de concordancia del artículo femenino con el sustantivo masculino, como vemos en el Ejemplo 5.

Estas observaciones actúan de anticipo a nuestro objeto de estudio: el tratamiento de las citas y de los textos literarios.

La relación textual entre el inglés y el español deja entrever la imagen del lector en español que tenían sus redactores, o la prisa con la que se producía el impreso. O la supuesta fidelidad que se le debía al texto inglés, que es necesario modificar pensando en el lector montevideano, menos habituado a la prensa y muy probablemente incapaz de leer el dominio en inglés del periódico.

\subsection{Literatura: omitid, que no entienden}

Como afirma Pedro Henríquez Ureña, "La literatura demostró su utilidad para la vida pública durante las guerras de la independencia. Con frecuencia tomó forma de periodismo $\mathrm{u}$ oratoria, o de ensayo político" (1980, p. 157). TSS/LES no es una excepción en lo que se refiere a la presencia de la literatura en sus páginas, bajo diversas formas: participación de William Scollay en la redacción, y citas de obras literarias completas o partes de ellas para reafirmar noticias de otro cuño.

El análisis comparativo de lo que ocurre con el texto en inglés y en español en lo que concierne a este aspecto específico reafirma la distancia entre ambos y una figuración distinta de cuán letrado sería el lector en cada caso.

Un ejemplo significativo de esta distancia es la omisión de las citas literarias en la columna en español, en el número 1, del 23 de mayo de 1807 , en la página 1 . Lo que se omite en español en el texto firmado por "Veritas" (que sería original en inglés según los estudios citados) es el verso de William Shakespeare perteneciente a Julius Caesar, acto 4, escena III (véase Ejemplo 6).

Hay aquí dos opciones: puede ser que quien oficiara de redactor/traductor en español no estuviera al tanto de la cita literaria que tenía entre manos, "pass by us as the idle wind", a pesar de que estuviera entre comillas en inglés. O que si, al comprenderla, decidiera suprimirla para el lector montevideano, subestimándolo.

\section{Ejemplo 6}

The exaggerations of malice we shall ever despise and the lispings of envy will "pass by us as the idle Despreciaremos siempre las exâgeraciones de wind" la malicia sin hacer caso alguno de calumnias ó murmuraciones envidiosas.

Fuente: Anáforas (1807a) 
Citas como "Give to Cesar that which is Cesar's", bíblica y probablemente más conocida, sí se mantiene en el número 7, del 4 de julio de 1807, en la página 3: "Dad al Cesar lo que pertenece al Cesar" (Anáforas, 1807f). Otro ejemplo de cita bíblica, pero tratada de distinta forma, está en el número 2, del 30 de mayo de 1807, en la página 1, cuando se refieren los Salmos (49:20) (véase Ejemplo 7).
Como se observa, la estrategia consiste en anular las comillas y eliminar la referencia al "perecer" de las bestias, minimizando la capacidad del lector en español de conectar el texto periodístico con el intertexto bíblico. El dejar de lado las citas, por desconocimiento, pereza o adaptación al público lector en español, llega a ser incluso más manifiesto en los versos de Hamlet, de Shakespeare, que "Veritas" cita en el

Ejemplo 7

which lifts him from a level with the "beasts that elevandole del nivel de las bestias perish"

Fuente: Anáforas (1807b).

número 2, del 30 de mayo de 1807, en la página 1 , que directamente no se traducen:

'an unweeded garden

"That grows to seed. Things rank \& gross

"Possess it merely" (in nature) (Anáforas, 1807 b, p. 1).

En este caso, simplemente se omiten los versos, y obviamente el potencial retórico que poseían en el texto en inglés, y se condensa en un mismo párrafo lo que en inglés estaba separado por la cita, como observamos en la propia página (véase Figura 9).

Nuevamente, encontramos la ausencia de versos correspondientes a Henry $v$, también de Shakespeare, acto v, escena III, que en la columna en inglés están al final de la noticia de una batalla inminente (véase Figura 10).

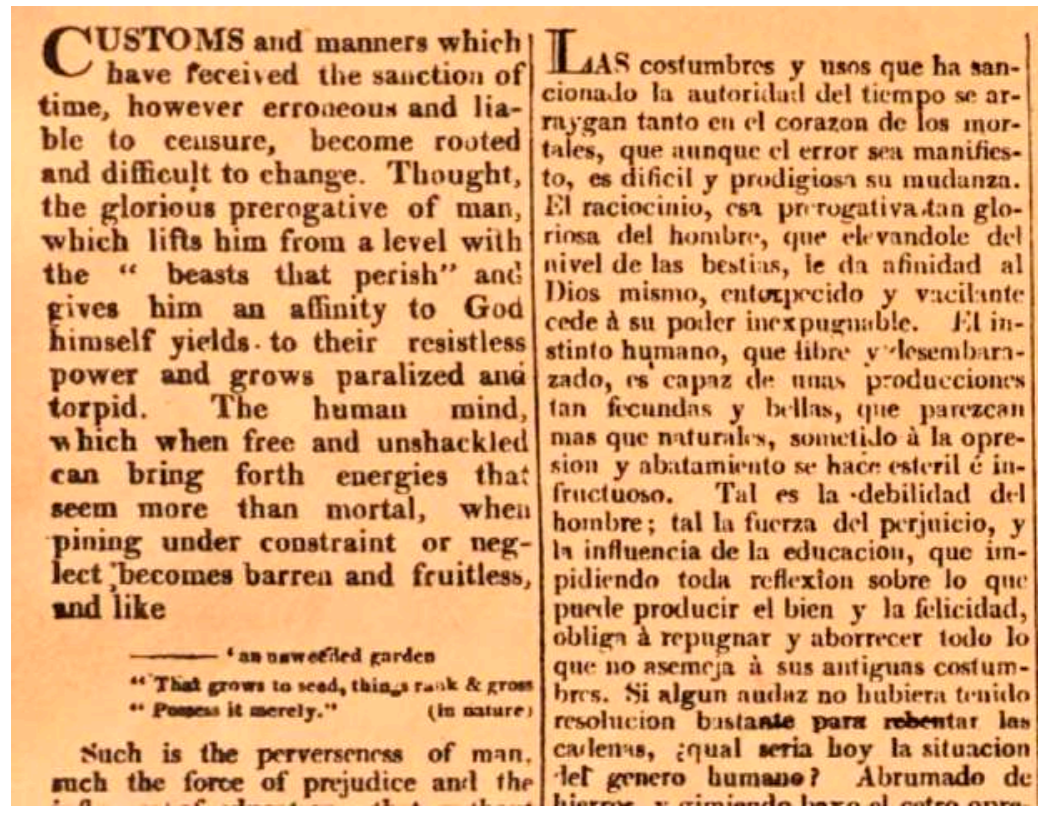

Figura 9. Eliminación de cita en The Southern Star/La Estrella del Sur, número 2, 30 de mayo de 1807, página 1 (recorte). Fuente: Anáforas (1807b). 
our present force and the gallantry and enthusiasm of Britons when fighting the battles of their King and Country, preclude the necessity of additional numbers. When inpelied by the feelings which ever animate the bosoms of $\mathrm{En}$ glishmen, every regiment is a host, and every man a hero. Should any one be so faint hearted as to wish with the hesitating Westmoreland for "' one ten thousand men from England," we feel confident that every Soldier and Sailor will exclaim with the gallant Harry :-

- "What's be that wishes, so?

"My cousin Westmoreland? - No my fair cousin; "If we are mark'd to die, we are enaugh

"To do our country lass; and if to live,

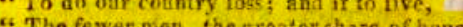

“No faith uny cos, with anta share of honor.

No faith my moz, wish anta man from England

" God's peace' I would not loseso great an hosor,

"As one man wore, methinks, wouldsharefrom me

"For the best hope I have.

"We would not die in that man's company,

"That fears his fellowship to die with us?

"He that outlives that dav, and comes sufe bome.

"Will stand a tip-toe when the day is nam'd.

"And rouse him at the sound.

"A And gentienen in England, now a-bed

"Shail think themselves accurs'd they were not (here,

On Tuesday last a flag of truce arrived 2 this place from Butenos Ayres, we un. derstand that he brought letters to bis Excellency the Commander of the Forces. yau. poro su cussango con las fuerzas que tenemos ya aqui, creemos que seran capazes para pelear con el valor y entusiasino que es natural à todo Bretanico en la guerra por su rey y patria; y serà por demas aqueste refuerzo esperado. Animados de los sentimientos de valor que viven siem re en el pecho de un Ingles cada regimiento es u: exercito, y cada soldado un héroe.

E1 Martes 16 del corriente llegó aqui un oficial parlamentario de Buenos-Ayres, el qual trajo cartas à su Exa el Comandante de las Fuerzas, haciendole en ellas propuestas para trater el cambio de algunos prisioneros de guerra, $y$ esto ofrecimiento se rehusó mediante no haberse cumplialo todaria los terminos de la Capitalaciom hecha con el Gen. Berresford. El sugeto fue traxo estos despachos del otro lado iel rio, sin duda tendria motivos diferentes para su viage dे este plaza : sin embargo estubo aqui sin ninguna reserva de muestra parte, en tal manera, que pulo tener una demostracion ocular de nuestras fuerzas, y del uso en que se pondrán en breve tiempo.

Es lastima que haya un numero tan grande de ladrones que molesten las inme-

Figura 10. Eliminación de cita en The Southern Star/La Estrella del Sur, número 5, 20 de junio de 1807, página 3 (recorte). Fuente: Anáforas (1807d).

En función de la diferencia entre el tratamiento de las citas literarias en una y otra lengua, y de estrategias de traducción que pasan en ocasiones por la mera supresión del texto literario en español, consideramos que hay una figuración sistemática de un lector en español menos ilustrado que el lector en inglés. Al mismo tiempo, la eliminación de las marcas literarias, y la readaptación gráfica y de contenido del texto en español, demuestran la dirección del flujo de traducción de un texto inglés más sofisticado hacia un español imbuido del prejuicio y la prisa del oficio periodístico.

\subsection{Red de colaboraciones poéticas}

A pesar del descuido o la intención de simplificar el texto en español, TSS/LES no deja de ofrecer ejemplos literarios correlativos en las dos lenguas. Con el propósito claro de establecer relaciones recíprocas entre las dos culturas, está la traducción al inglés del soneto que canta Cardenio en el Quijote, de Miguel de Cervantes, realizada por parte de un lector presumiblemente inglés.Nótese, eso sí, que la autoría está omitida en el soneto original en español (por descuido o desconocimiento, lo que en definitiva tiene el mismo resultado sobre el texto en español) (véase Figura 11).

En otro sentido, la inclusión del poema "Recuerdos de un ausente" de Gaspar María de Nava, conde de Noroña (1760-1815) en el número 4, del 13 de junio de 1807, página 4 (Anáforas, 1807c), proviene de un original en español (ligado a la propia traducción del poema homónimo de Ibn al-Farid que Noroña publica en Poesías asiáticas puestas en verso castellano, de 1833 , en la página 150 (Noroña, 2018)). De todos modos, llama la atención que en inglés se coloque el nombre de "Petrarca" al pie del soneto, mientras que en español se omite esa información. 

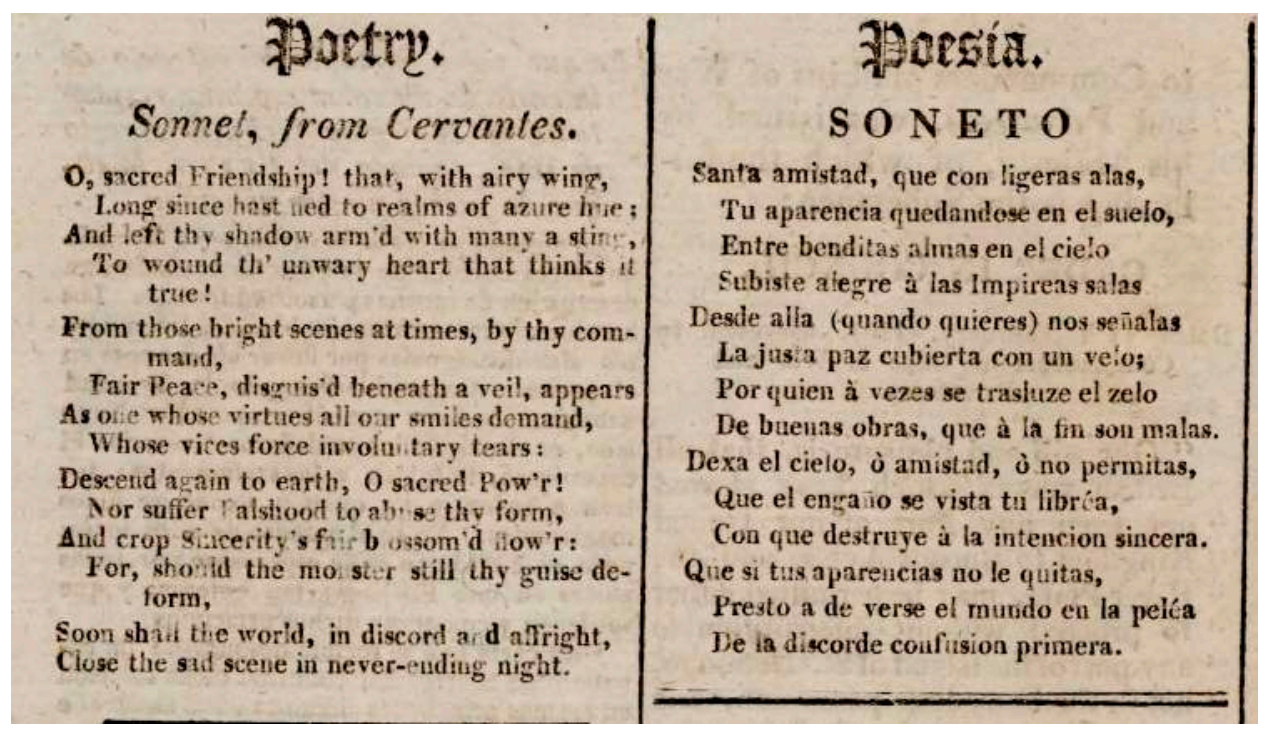

Figura 11. Ejemplo literario correlativo en las dos lenguas en The Southern Star/La Estrella del Sur, número 1, 23 de mayo de 1807, página 4 (recorte). Fuente: Anáforas (1807a).

Más adelante hay una nota que aclara: "We return our thanks to Pretarca for his translations and otherfavors", por lo que se infiere que "Petrarca" es el seudónimo del traductor ${ }^{20}$ del soneto del conde de Noroña. Es más, en el número 6, del 27 de junio, encontramos que se incluye un poema de su autoría en la sección de "Original Poetry for the Southern Star" (Anáforas, 1807e, p. 4), lo que deviene en una serie de reescrituras en las que creación y traducción están fuertemente relacionadas.

Dando cuenta también de la red de colaboraciones que hacía posible el impreso, en el número 7 , página 4 , del 4 de julio de 1807 , se ofrece una "Horace's Ode", traducida por Mr. Gowland (Anáforas, 1807f), que había aparecido previamente como comerciante vendedor de mercancías ("Thomas Gowland") en el número 4, del 13 de junio de 1807, en la página 4 (Anáforas, 1807c); y como donante del fondo para ayuda a los soldados ingleses,

20 Valdría otro estudio para el análisis de la traducción del soneto, que en inglés mantiene cierto esquema rítmico, y que, por la periodicidad semanal del impreso, debe de haber sido realizada en tiempo récord. en el número 5, del 20 de junio de 1807, en la página 3 (avisos solo en inglés, al igual que la traducción de la oda) (Anáforas, 1807d).

Si en el plano de la redacción vimos la relación entre el traducir y el editar como operaciones guiadas por una figuración de lector en cada lengua bastante precisa, en las citadas colaboraciones literarias observamos que hay, desde la redacción, una línea editorial que privilegia la inclusión de literatura, y no solo en inglés; así como una red de colaboradores (y editores) para quienes la creación y la traducción forman parte del reescribir como un todo.

\subsection{Metadiscurso sobre la traducción}

Ahora nos interesa articular lo discutido en torno a la omisión de literatura y a la red de colaboraciones literarias con un elemento crucial: lo que en la redacción de TSS/LES se entendía por "traducción", la valoración de su importancia y los juicios de valor que orientaban su praxis.

La poesía de la colaboradora "Maria Theresa", cuya identidad es aún desconocida, no se publica traducida al español, aunque encontramos 


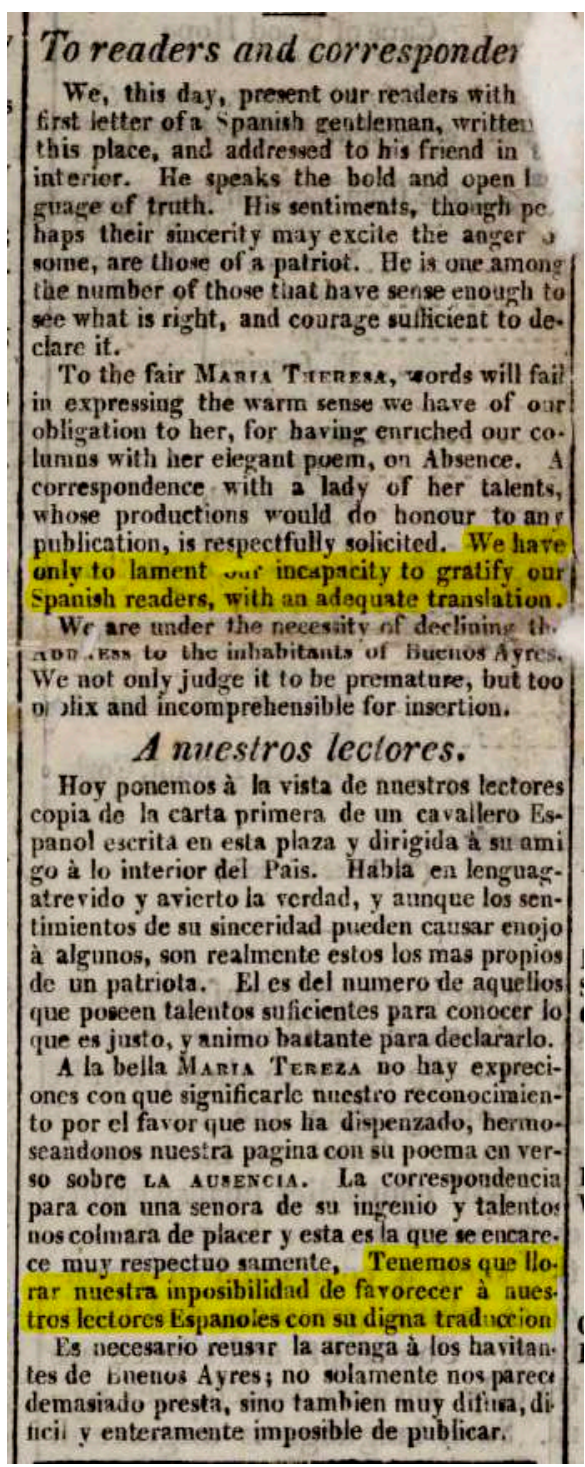

Figura 12. "A nuestros lectores", en The Southern Star/La Estrella del Sur, número 2, 30 de mayo de 1807, página 4 (recorte). Fuente: Anáforas (1807b).

una referencia a esa ausencia, supuestamente provocada por la falta de tiempo o de una persona idónea para realizarla. Lo cierto es que los redactores estiman importante dejar en claro la preocupación por una traducción "adequate"/ "digna" en español: "We have only to lament our incapacity to gratify our Spanish readers with an adequate translation" / "Tenemos que llorar nuestra imposibilidad de favorecer à nuestros lectores Espanoles con su digna traduccion" (Anáforas, 1807b, p. 4). Véase, en la Figura 12, el comentario en la propia columna.

Estas advertencias en TSS/LES revelan inconsistencias entre el interés y la preocupación por la traducción de los textos poéticos y su efectiva realización, un oscilar entre reconocer la importancia de la literatura en las páginas, pero también que su publicación estaría sujeta a los avatares de una redacción precaria en el Montevideo de principios de siglo XIX.

Es que, como se indica en la misma sección citada, pero del número 1 , del 23 de mayo de 1807, en la página 4 en inglés y página 3 en español, "we shall seldom be bold enough to attempt a translation of poetry" / "muchas veces no tendremos lugar vastante para traducir obras poéticas ni animo para esta empresa" (Anáforas, 1807a, p. 4 en inglés y p. 3 en español), afirmación que deja entrever la rapidez con que debía redactarse el periódico.

Encontramos un juicio igualmente significativo en torno a la traducción y su imposibilidad o fracaso en las mismas páginas (véase Ejemplo 8).

\begin{tabular}{l:l} 
Ejemplo 8 & {$[\ldots]$ conocemos que } \\
\hdashline The most beautiful & los sentimientos mas \\
sentiments and loftiest & vellos, y figuras mas \\
images, when an & sublimes, pierden su \\
unskilful hand attempts & $\begin{array}{l}\text { energia y se desfiguran, } \\
\text { to transplant them to a } \\
\text { foreign idiom, exhibit the } \\
\text { caricature features of } \\
\text { burlesque and deformity. }\end{array}$ \\
Fuente: Anáforas $(1807 \mathrm{a})$. &
\end{tabular}

Al mismo tiempo, como se muestra en la Figura 13, desde la redacción se motiva a los lectores a colaborar con traducciones, que se recibirán con "indecible complacencia".

Es significativo, y hasta irónico, que haya esa preocupación por la traducción de poesía, en la medida en que no encontramos el mismo afán por dar cuenta de la literariedad de las columnas de "Veritas", eminentemente políticas, como vimos antes. 


\section{To readers and correspondents. \\ The copy of the letters we have received from our friend $P$. shall have due insertion. \\ To the gentleman who favoured us with a translation of the beautiful Sonver, from Don Quixote, we render our sincerest acknow- ledgments. Any more favours of the same nature, which he may be pleased to confer, wili be gratefully received. We shall ever, cheerfully dedicaie a corner of our paper to the service of the Muses. Keing convinced of the truth of Horace's maxim, "Poela na- citur not fit," we shall seldom be bold enough to attempt a transiation of poetry. The most beautiful sentiments and loftiest images, when an unskiful hand attempts to transplant them to a foreign illiom, exhibit the caricaiure fea- tures of buriesque and deformity.}

\section{A nuestros lectores.}

Ias copias de las cartas con que nos ha favorecido a: estro amigo $P$. tendràn sa lugar correspondiente en la gazeta siguiente d esta.

Al cavallero que nos ha favorecido mandan. donos la traduccion de un Sonexo hermosisino de D. Quixote de la Mancha, le tribufamos nuestro agradecimiento; y otro qualesquier favor de esta clase que tenga la vondad de dispenzarnos lo recebiremos con indecible complacencia : dedicaremos siempre un lugar en nues'ra gazeta al servicio de lasMrusas. Hallandonos convencidos de la realidad de la seritencia de Horacio, "qui Poeta nacitur non fit" muchas veces no tendremos lugar vastante para traducir obras poeticas ni avimo para esta empresa, pues conocemos que los sentimientos mas vellos, y figuras mas sublimes, pierden su energia y e disigurau, quando sontraducida sin perfeccion.

Figura 13. Solicitud de colaboración con traducciones para The Southern Star/La Estrella del Sur, número 1, 23 de mayo de 1807, página 4 en inglés y página 3 en español (recorte). Fuente: Anáforas (1807a).

El interés en la literatura como arte elevada es significativo y corresponde, en tanto introducción de elementos estéticos, con lo que Pierre Bourdieu definió como "una expresión distintiva de una posición privilegiada en el espacio social, cuyo valor distintivo se determina objetivamente en la relación con expresiones engendradas a partir de condiciones diferentes" (1998, p. 53). Creemos que el que las "condiciones diferentes" correspondan justamente al espacio de un vacío mediático, no hace más que potenciar el efecto de la introducción de literatura en las páginas de TSS/LES, su valor distintivo. En este caso, hay sí la valoración de la literatura, pero sobre todo en la línea editorial del espacio del texto en inglés, no tanto así en aquel espacio destinado a los lectores en español.

Para reafirmar esta idea de una línea editorial afín a la literatura como arte elevada en TSS/LES, por más incipiente que fuera, cabe citar un ejemplo solamente en inglés, en la misma sección "To readers and correspondents" que recién analizamos, un comentario de tono moral y estético, ahora meramente crítico y ya no traductivo, sobre otro de los colaboradores con seudónimo del impreso (véase Figura 14).

\begin{abstract}
To readers and correspondenls.
We have to acknowledge the receipt of several communications from our correspondents----which shall meet with due attention.

What Publicus calls a " $\mathrm{Po}$ litical Sketch" we call nonsense. We thank our friend C. X. for his hints, and assure him we shall make use of them.

We sincerely lament the melancholy condition into which the tender hearted A Myntas seems to have fallen.--To judge of the soundness of his intellects by the rottenness of his composition, we should certainly be inclined to pronounce him a fit subject for the hospital of lunatics. His poem is indeed prose run-mad. The best advice which we can possibly give him, is to throw his pen in the fire and take salts.
\end{abstract}

Figura 14. Línea editorial afín a la literatura como arte elevada en The Southern Star/ La Estrella del Sur, número 6, 27 de junio de 1807, página 4 (recorte). Fuente: Anáforas (1807e). 
Este pequeño aviso es significativo, una vez más, de la red de colaboradores de TSS/LES no solamente en asuntos políticos y estratégicos, sino también literarios y traductivos. La recepción de "several communications" nos retrata el interés que suscitó el periódico entre sus lectores, ávidos por colaborar en el terreno de lo estético. Habla, en paralelo, de una línea editorial que privilegia un tipo preciso de literatura, preferencia que no se esconde y aparece en textos al margen como el citado. Ello, sumado a las preocupaciones en torno a la traducción que expusimos, deja en evidencia que la omisión de ciertos textos literarios en la columna en español no es algo casual, sino deliberado, fruto de una figuración del lector en español como menos sofisticada y erudita.

\section{Conclusiones}

El análisis de la relación establecida entre el inglés y el español a raíz de la edición bilingüe en TSS/LES revela un estrecho vínculo con los acontecimientos políticos en el Río de la Plata a comienzos del siglo XIX y con los condicionamientos mediáticos y materiales de este órgano de prensa. El abordaje del objeto de estudio por parte de los estudios de traducción se revela necesario con respecto, y como contrapunto, a la bibliografía desde otras disciplinas. Ello ocurre sobre todo en torno a las afirmaciones, en ocasiones normativas, sobre la traducción del texto entre el inglés y el español. Lejos de una correspondencia uno a uno, el análisis comparado inglés-español del texto de TSS/LES demuestra una cierta independencia de los dos dominios, alimentada por el hecho de que no todos los lectores leían en las dos lenguas.

Por cierto, el trabajo arroja que existe, además, una gran variabilidad en formato, contenidos y elementos ortotipográficos entre los dominios del inglés y el español. Si, por una parte, es clave entender lo que ocurre en la traducción teniendo en cuenta el público de destino, por otra, los condicionamientos culturales y la función del impreso, siguiendo a Schäffner (2012), también ha sido importante volver sobre las características materiales de TSS/LES y cómo impactan, en qué y cómo se traduce.

Con relación al bilingüismo, la escisión de lo inglés y lo español es relevante para el presente de esta investigación, en tanto la convivencia de la página fuerza una relación entre los dos ámbitos que se revela ligada a figuraciones y estereotipos de cómo sería el lector en cada lengua. En lo que concierne al pasado, el aviso de clases de inglés (Anáforas, 1807e, p. 4) que expusimos es ilustrativo al respecto: tarde o temprano los montevideanos hablarían más de una lengua, si las invasiones se hubieran sostenido en el tiempo. Vale preguntarse, entonces, si habría quienes leían el impreso con detenimiento en las dos lenguas y si se daban cuenta, con cierta estupefacción, de las ausencias que había en el español fundamentalmente.

La configuración de una y otra columna, y sobre todo la extensión de los textos en cada lengua, determinan estrategias precisas en cuanto a cómo ocurre la traducción en las páginas de TSS / LES. No obstante, la traducción en un sentido y otro, casi siempre anónima, también se orienta por lineamientos editoriales, que no pueden ser explicados como decisiones individuales de los traductores y deben entenderse en el marco de las "Invasiones Inglesas" a la ciudad de Montevideo.

Siguiendo a Acree (2007), consideramos que las estrategias descritas obedecen a una intención de localizar el contenido de TSS/LES de acuerdo con el público lector de cada columna. La presencia de extractos de prensa extranjera, las colaboraciones de individuos de variada procedencia, e incluso los fragmentos de discurso sobre la traducción que encontramos, vienen a reafirmar el ánimo internacionalista del impreso, su afán de sofisticación intelectual, al menos en el espacio del inglés, y un descuido sistemático del espacio del español.

El análisis del tratamiento de la traducción de las citas y de los textos literarios en TSS/ 
LES que realizamos permite concluir que, efectivamente, hay en el texto en español menos atención por reproducir la variación tipográfica, las referencias y la intertextualidad que se despliegan en el texto en inglés. Afirmar que este último podría ser el texto primero en los casos analizados - aquellos en que hay una recurrencia a la literaturaparece razonable, por las adaptaciones gráficas y textuales que muestra el español al respecto. De alguna forma, ello podría responder a la precariedad de la redacción y a los plazos a los que somete la periodicidad semanal. Sin embargo, si articulamos estos datos con los pequeños fragmentos en los que detectamos un metadiscurso sobre la traducción, como las disculpas por no poder ofrecer una traducción "digna" del poema de la colaboradora "Maria Theresa", por no tener espacio ni "ánimo" para intentarlo o incluso porque los sentimientos más altos serían traicionados al momento de una traducción defectuosa, llegamos a concluir que desde la redacción existía la noción de la importancia de la traducción y del valor de la literatura como diferencial del periódico. Por otra parte, creemos que estos datos terminan por dejar en evidencia que no había intención de ofrecer el mismo grado de literariedad en los ámbitos del inglés y el español, y que este último dominio se vio afectado por una figuración del lector como menos sofisticado y digno de ofrecerle tales traducciones de literatura extranjera.

En paralelo, podemos pensar que los editores contaban con el hecho de que los lectores en español no leerían el texto en inglés, por lo que estas operaciones no tendrían el riesgo de ser descubiertas y ser entendidas como una ofensa a los lectores locales.

Por último, después de este análisis parcial de la traducción y el discurso sobre ella en TSS/LES, quedan varios frentes abiertos para continuar la investigación, ya sea en la consideración de las columnas que han sido apuntadas como originales en español y las estrategias de traducción al inglés, como en el detenimiento en las estrategias generales de traducción y una cuantificación al respecto que pueda iluminar los resultados de este trabajo, o contradecirlos.

\section{Referencias}

Acree, W. G. (2007). La otra batalla: The Southern Star, la Gazeta de Montevideo y la revolución de las formas de comunicación en el Río de la Plata. En A. Frega y B. Vegh (Eds.), En torno a las "invasiones inglesas": relaciones politicas $y$ culturales con Gran Bretaña a lo largo de dos siglos (pp. 13-22). Universidad de la República, Facultad de Humanidades y Ciencias de la Educación.

Álvarez Ferretjans, D. (2008). Historia de la prensa en el Uruguay. Desde la Estrella del Sur a Internet. Fin de Siglo.

Anáforas (1807a). Número 1 de The Southern Star/La Estrella del Sur, 23 de mayo de 1807. https://anaforas.fic.edu.uy/jspui/handle/123456789/3193

Anáforas (1807b). Número 2 de The Southern Star/La Estrella del Sur, 30 de mayo de 1807. https://anaforas.fic.edu.uy/jspui/handle/123456789/3192

Anáforas (1807c). Número 4 de The Southern Star/La Estrella del Sur, 13 de junio de 1807. https://anaforas.fic.edu.uy/jspui/handle/123456789/3190

Anáforas (1807d). Número 5 de The Southern Star/La Estrella del Sur, 20 de junio de 1807. https://anaforas.fic.edu.uy/jspui/handle/123456789/3189

Anáforas (1807e). Número 6 de The Southern Star/La Estrella del Sur, 27 de junio de 1807. https://anaforas.fic.edu.uy/jspui/handle $/ 123456789 / 3188$

Anáforas (1807f). Número 7 de The Southern Star/La Estrella del Sur, 4 de julio de 1807. https://anaforas.fic.edu.uy/jspui/handle $/ 123456789 / 3187$

Anáforas. (s. f.). https://anaforas.fic.edu.uy/jspui/

Ares, F. E. (2010). Expósitos: la tipografia en Buenos Aires 1780-1824. Dirección General Patrimonio e Instituto Histórico. 
Bastin, G. L. y Iturriza, M. G. (2008). La traducción como elemento creador de identidad en la prensa independentista de Venezuela (1808-1822). Trans. Revista de Traductología, (12), 81-94. https://doi. org/10.24310/TRANS.2008.v0i12.3130

Block de Behar, L. (2015). La Cruz del Sur (Uruguay, 1924-1931): Una visión astral y austral en la encrucijada de contradicciones y coincidencia. En Derroteros literarios: temas y autores que se cruzan en tierras del Uruguay (pp. 301-314). Ediciones Universitarias.

Bourdieu, P. (1998). La distinción. Criterio y bases sociales del gusto. Santillana.

Canter, J. (1948). Introducción. En Biblioteca de impresos raros americanos (tomo 1 , pp. xxv-lvi). Universidad de la República, Facultad de Humanidades y Ciencias, Instituto de Investigaciones Históricas.

Castellanos, D. (1943). La Estrella del Sur en campo de hipótesis. Revista del Instituto Histórico y Geográfico del Uruguay, Tomo xVIII, 12-14.

Doorslaer, L. van. (2010). Journalism and translation. En Y. Gambier, y L. van Doorslaer (Ed.), Handbook of translation studies (vol. 1, pp. 180-184). John Benjamins.

Gambier, Y. y Doorslaer, L. van. (2016). Border crossings. Translation studies and other disciplines. John Benjamins.

González, A. (1942). Prólogo. En The Southern Star / La Estrella del Sur. Ed. facsimilar (pp. 17-30). A. Barreiro y Ramos.

González, H. (2007). Prólogo. En La Estrella del Sur $=$ The Southern Star (pp. 9-11). Biblioteca Nacional.

Guzmán, C. (2015). Vectors of exchange: Translation praxis in Cuadernos de Marcha and Revista Casa de las Américas. TTR, 28(1-2), 91-108. https://doi.or$\mathrm{g} / 10.7202 / 1041651 \mathrm{ar}$

Guzmán, C. (2017). El Caribe se traduce: La traducción como praxis descolonial en las revistas Tropiques, Bim y Revista Casa de las Américas. Mutatis Mutandis. Revista Latinoamericana de Traducción, 10(1), 167-181. https://doi. org/10.17533/udea.mut.v10n1a07

Guzmán, C. (Ed.). (2019). Introduction to the special edition: Translation and/in periodical publications. Translation and Interpreting Studies. 14(2), 169-173. https://doi.org/10.1075/tis.14.2

Henríquez Ureña, P. (1980). Las corrientes literarias en la América Hispánica. En Obras completas (tomo x, pp. 41-308). UNPHU.

Herrera, V. (2008). Vestigios clásicos en The Southern Star - La Estrella del Sur. En J. Introini y V. Herrera (Eds.), La ninfa en la selva. Literatura uruguaya y tradición clásica (pp. 25-34). Universidad de la República, Departamento de Publicaciones de Facultad de Humanidades y Ciencias de la Educación.

Hewson, L. (1993). The bilingual edition in translation studies. En R. Sarkonak y R. Hodgson (Eds.), Writing in stereo: Bilingualism in the text (pp. 138-161). Sharon Helmer Poggenpohl.

HISTAL (s. f.). Groupe de recherche HISTAL. Histoire de la traduction en Amérique latine. www.histal.net/es

Iturriza, M. G. (2008). Traducción de la prensa extranjera e intertextualidad en el periodo preindependentista de la Gaceta de Caracas. TRANS, (12), 95-120.

Iturriza, M. G. (2011). ¿Révolution o resolución? Omisiones, supuestos y simulacros de los transductores de L'Ambigu y la Gaceta de Caracas. En A. Pagni, G. Payàs y P. Willson (Eds.), Traductores y traducciones en la historia cultural de América Latina (pp. 81-128). Universidad Nacional Autónoma de México.

Littau, K. (2016). Translation and the materialities of communication. Translation Studies, 9(1), 82-96. https://doi.org/10.1080/14781700.2015.1063449

Marco, M. Á. de (2006). Historia del periodismo argentino: desde los origenes hasta el centenario de Mayo. Educa.

María, I. de. (1957). La imprenta 1807-1838. En Montevideo antiguo: tradiciones y recuerdos (tomo 2 , pp. 61-78). Ministerio de Educación y Cultura (Uruguay).

Martini, M. P. (1998). Francisco Antonio Cabello y Mesa, un publicista ilustrado de dos mundos (17861824). Instituto de Investigaciones sobre Identidad Cultural, Universidad del Salvador.

McLuhan, M. (1962). The Gutenberg galaxy. The making of typographic man. University of Toronto Press. 
Mitchells, C. (Spring 2010). Translation and materiality: The paradox of visible translation. (Translating Media. Annual Cinema \& Media Studies Graduate Student Conference Issue). Spectator, 30(1), 23-29.

Navarro, A. (2011). La Gaceta de Caracas, traduction et indépendance au xixe siècle. Meta, 56(1), 81-100. https://doi.org/10.7202/1003511ar

Noroña, G. M. de N. Á., Conde de. (2018). Poesías asiáticas puestas en verso castellano. Biblioteca Virtual Miguel de Cervantes. http://www. cervantesvirtual.com/obra/poesias-asiaticas

Pagni, A., Payàs, G. y Willson, P. (2011). "Presentación”. En A. Pagni, G. Payàs y P. Willson (Eds.), Traductores y traducciones en la historia cultural de América Latina (pp. 7-11). Universidad Nacional Autónoma de México.

Peltier, J.-G. (1807, junio 27). "The Catechism of Bonaparte" y "El Catezismo de Bonaparte". La Estrella del Sur, (6), 2.

Pierrotti, N. (2007). El nacimiento de una forma de ser. Una nueva visión sobre la construcción de las mentalidades en el Montevideo colonial (1726-1814). Estudos Ibero-Americanos, 33(2), 35-50. https://doi.org/10.15448/1980864X.2007.2.2391

Pierrotti, N. (2008). Leer, interpretar y actuar. La influencia del libro en el pensamiento colonial montevideano (1724-1830). Humanidades. Año 8-9 (1), 133-154.

Praderio, A. (1962). Índice cronológico de la prensa periódica del Uruguay 1807-1852. Instituto de Investigaciones Históricas, Facultad de $\mathrm{Hu}-$ manidades y Ciencias.

Real Academia de la Historia (2018). Francisco Antonio Evaristo Cabello y Mesa. http:// dbe.rah.es/biografias/52927/francisco-antonio-evaristo-cabello-y-mesa

Rodó, J. E. (1958). La prensa de Montevideo. En Anáforas. Biblioteca digital de autores uruguayos. Seminario de Fundamentos Lingüísticos de la Comunicación, Facultad de Información y
Comunicación, Universidad de la República. http://www.autoresdeluruguay.uy/biblioteca/Jose_Enrique_Rodo/lib/exe/fetch.php?media=rodo_j._e._-_la_prensa_de_montevideo_1909_.pdf

Sarkonak, R. y Hodgson, R. (1993). Writing in stereo: Bilingualism in the text. Sharon Helmer Poggenpohl.

Schäffner, C. (2012). Rethinking transediting. Meta, 57(4), 866-883. https://doi.or$\mathrm{g} / 10.7202 / 1021222 \mathrm{ar}$

Stetting, K. (1989). Transediting - A New term for coping with the grey area between editing and translating. En G. Caie (Eds.), Proceedings from the Fourth Nordic Conference for English Studies (pp. 371-382). Universidad de Copenhague, Dinamarca.

Torres, A. (2007). Una lectura excéntrica del discurso periodístico colonial. The Southern Star y la Gazeta de Montevideo. En A. Frega y B. Vegh (Eds.), En torno a las "invasiones inglesas": relaciones políticas y culturales con Gran Bretaña a lo largo de dos siglos (pp. 31-38). Universidad de la República, Facultad de Humanidades y Ciencias de la Educación.

Valdeón, R. (2018). On the use of the term 'translation' in journalism studies. Journalism, 19(2), 252-269. https://doi. org/10.1177/1464884917715945

Willson, P. (2004a). La constelación del Sur. Traductores y traducciones en la literatura argentina del siglo $X X$. Siglo XXI.

Willson, P. (2004b). Página impar: el lugar del traductor en el auge de la industria editorial. En S. Saítta (Dir.), Historia crítica de la literatura argentina (vol. 9, pp. 123-142). Emecé.

Willson, P. (2011). Paraísos perdidos: la traducción en Caras y Caretas (1898-1908). En A. Pagni, G. Payàs y P. Willson (Eds.), Traductores y traducciones en la historia cultural de América Latina (pp. 31-44). Universidad Nacional Autónoma de México. 